\title{
Comparison of Global Precipitation Estimates across a Range of Temporal and Spatial Scales ${ }^{\mathcal{O}}$
}

\author{
MARIA GEHNE \\ Cooperative Institute for Research in Environmental Sciences, University of Colorado \\ Boulder, Boulder, Colorado \\ Thomas M. HAMiLl AND GeORGE N. Kiladis \\ Physical Sciences Division, NOAA/Earth System Research Laboratory, Boulder, Colorado \\ KEVIN E. TRENBERTH \\ National Center for Atmospheric Research, ${ }^{a}$ Boulder, Colorado
}

(Manuscript received 28 August 2015, in final form 8 July 2016)

\begin{abstract}
Characteristics of precipitation estimates for rate and amount from three global high-resolution precipitation products (HRPPs), four global climate data records (CDRs), and four reanalyses are compared. All datasets considered have at least daily temporal resolution. Estimates of global precipitation differ widely from one product to the next, with some differences likely due to differing goals in producing the estimates. HRPPs are intended to produce the best snapshot of the precipitation estimate locally. CDRs of precipitation emphasize homogeneity over instantaneous accuracy. Precipitation estimates from global reanalyses are dynamically consistent with the large-scale circulation but tend to compare poorly to rain gauge estimates since they are forecast by the reanalysis system and precipitation is not assimilated. Regional differences among the estimates in the means and variances are as large as the means and variances, respectively. Even with similar monthly totals, precipitation rates vary significantly among the estimates. Temporal correlations among datasets are large at annual and daily time scales, suggesting that compensating bias errors at annual and random errors at daily time scales dominate the differences. However, the signal-to-noise ratio at intermediate (monthly) time scales can be large enough to result in high correlations overall. It is shown that differences on annual time scales and continental regions are around $0.8 \mathrm{~mm} \mathrm{day}^{-1}$, which corresponds to $23 \mathrm{~W} \mathrm{~m}^{-2}$. These wide variations in the estimates, even for global averages, highlight the need for better constrained precipitation products in the future.
\end{abstract}

\section{Introduction}

Gridded estimates of daily (or higher frequency) global precipitation are becoming more and more needed for applications such as model validation, input for land

Supplemental information related to this paper is available at the Journals Online website: http://dx.doi.org/10.1175/ JCLI-D-15-0618.s1.

${ }^{a}$ The National Center for Atmospheric Research is sponsored by the National Science Foundation.

Corresponding author address: Maria Gehne, CU Boulder CIRES/NOAA, Cooperative Institute for Research in the Environmental Sciences, NOAA/ESRL Physical Sciences Division, R/PSD1, 325 Broadway, Boulder, CO 80305.

E-mail: maria.gehne@noaa.gov surface models, or extreme-event characterization. Detailed knowledge about current precipitation distributions is also necessary to quantify changes in precipitation estimated by global warming scenarios, which tend to be described as changes in the mean and tails of the distribution. All of these applications assume that an accurate or at least adequate estimate of these distributions is obtainable.

Because there is a strong connection between temporal and spatial variability of precipitation, and variability of precipitation decreases with both longer time and larger spatial averages (Bell et al. 1990), what comprises an adequate estimate depends on the application. On monthly scales global precipitation estimates have been used to assess the global water cycle (Trenberth et al. 2007; Rodell et al. 2015), to study the 
covariability of precipitation and surface temperature (Trenberth and Shea 2005; Gu and Adler 2011), and to assess the imbalance between global precipitation and evaporation (Schlosser and Houser 2007; Trenberth and Fasullo 2013). Datasets that are able to resolve monthly variability at subcontinental spatial scales are suitable for estimates of the global water cycle. For many other applications, higher temporal (submonthly) and spatial $(<100 \mathrm{~km})$ resolution is needed. Validation of model forecast precipitation requires datasets with resolution similar to or higher than the model output, which can range from a few kilometers to several degrees, and hourly to multiday depending on the model used (Hamill 2012; Brown et al. 2012; Lindvall et al. 2013). For example, hourly resolution sets a good compromise between what is meaningful in models and useful for extremes. Station data are also used for model verification, but this approach depends on a high enough station density in the verification region (Gutowski et al. 2003). One of the fundamental outputs of land surface models, soil moisture, is highly variable in space and its spatial patterns depend strongly on the precipitation forcing the model even down to a resolution of $2 \mathrm{~km}$ (McLaughlin et al. 2006). In general, for land surface models at coarser resolutions (e.g., T382) hourly precipitation data are given as input and interpolated to the model time step of 15 or $20 \mathrm{~min}$ (Liu et al. 2011; Meng et al. 2012). Observed extreme precipitation events are usually highly localized in space and time, involving scales on the order of minutes to a few hours and several kilometers, especially in the tropics and during summer over land. For example, because of the transient nature of convection, resolving the very high rates in thunderstorms requires temporal resolution of hours or even minutes. To resolve the more extreme precipitation intensity events and accurately estimate the tails of the distribution, data at a resolution of 10-min intervals and about $1 \mathrm{~km}$ thus might be needed (Haerter et al. 2010). To accurately identify the mean diurnal cycle, hourly time steps are desirable to resolve the evolution of precipitation throughout the day.

Estimates of precipitation from individual rain gauges exist in many locations, but these are point values and apply only for the location they were collected. Gridded rain gauge-based analyses of precipitation are available over the global land areas, with the estimates assumed to be representative for a given area. However, large land and especially oceanic areas on the globe are very sparsely covered by rain gauges. This is problematic, because in sparsely sampled areas using interpolation between rain gauge locations to obtain a gridded analysis will introduce errors. In addition, rain gauge estimates are thought to underestimate precipitation rates due to undercatch in windy or snow conditions (e.g., Peterson et al. 1998; Adam and Lettenmaier 2003; Sevruk et al. 2009; Rasmussen et al. 2012, and references therein). Another issue is that precipitation measurements are usually reported only once or twice a day, which affects the resolution of both rates and totals, because the longer the precipitation is left in the gauge the greater the potential is for some of it to evaporate. Other options for global precipitation estimates that provide higher spatial and temporal resolution are based on satellite data. Most quasi-global high-resolution precipitation estimates are available at $3 \mathrm{~h}$ and $0.25^{\circ}$ resolution. While some of these datasets have versions at $4-\mathrm{km}$ and 30-min resolution, then missing data is more of an issue, which can be alleviated at the coarser resolution due to averaging. Data at $3 \mathrm{~h}$ and $0.25^{\circ}$ are marginally adequate to resolve the diurnal cycle (as mentioned above, hourly is better) and mesoscale systems but are still too coarse to resolve individual convective extreme events. Most satellite-based datasets have time series of less than 15 years (with one recent exception; see section 2), which is not long enough to estimate trends or a robust climatology. Note also that the data sources used in many satellite-based precipitation estimates change over time, mixing data source trends and real trends.

Precipitation estimates from satellite retrievals are inferred from infrared (IR) or microwave (MW) measurements rather than measured directly. IR measurements, which tend to be from geostationary satellites, have high spatial and temporal resolution, while MW or radar measurements are obtained from polar-orbiting satellites with much sparser sampling (Wolff and Fisher 2008). Global reanalyses offer another way to estimate global precipitation with the advantage that they synthesize many different data sources. However, while the underlying first-guess model is dynamically consistent, adjustments to assimilated data result in a product that is not necessarily mass or energy conserving. Precipitation in particular is often heavily dependent on the previous forecast cycle's first guess, which is contaminated by model bias. In addition, the spatial resolution is limited to that of the reanalysis.

There are several important questions users of these datasets need to ask. The most important one, obviously, is this: Which of these estimates is closest to the truth? There is no clear answer to this question. The conclusion of several precipitation intercomparison projects was that no one methodology is superior to the others (Kidd and Huffman 2011). In an early study Smith et al. (1998) showed that for regional comparisons, uncertainty in the ground validation data can be larger than the passive microwave (PMW) algorithm bias in many cases. They also showed that the 
differences in estimated rain rates are mainly due to how the more intense rain rates are calculated and how strict the screen is (precipitating vs dry pixels).

On monthly time scales for global analyses, Adler et al. (2001) show that merged analysis products, using more than one satellite source and adjusted to rain gauges, are superior to single source products. Without the adjustment to rain gauges, large biases existed over the southern Great Plains in the United States for the first generation of high-resolution precipitation products (HRPPs) (Sapiano and Arkin 2009). Even rain gaugeonly datasets have large differences; in the context of drought, using one or another dataset can result in an increase or decrease in the determination of drought conditions (Trenberth et al. 2014). The main conclusion from these studies is that there is no one best product; there is only the most appropriate product for a certain purpose. For example, studies at different locations and different seasons will likely benefit from using the product that has been shown to do well under those circumstances. If the emphasis is on consistency of precipitation with circulation patterns, then reanalysis products combined with observed precipitation may be the best choice. In addition, several other issues are not addressed in these previous studies, such as whether there are systematic biases among the HRPPs on the global scale. In all cases it is important for the user to know what the systematic differences are in the precipitation estimates of different products. To answer this question it is necessary to first quantify the differences among the datasets and the different estimation approaches. Are there biases particular to a certain approach to precipitation estimation? How do the distributions differ? And, given all the different estimates, is there a way to quantify the uncertainty associated with them? In terms of time series length, studies that deal with multiannual assessments of precipitation are rare (Prat and Nelson 2015), which is why we focus on datasets with more than 10 years of overlap. And while there are numerous examples of local and regional comparisons between datasets (e.g., Gutowski et al. 2003; Sohn et al. 2010; Kidd et al. 2012), here we focus on products that span the globe in longitude.

The aim of this study is not to determine which precipitation dataset is closest to the absolute truth, since that is impossible, but rather to identify strengths and shortcomings of the datasets, and to provide some guidance as to which estimates are likely to perform better in certain situations. Because distributions of precipitation are highly dependent on the resolution of the data used to compute them, daily or higher temporal resolution is better suited for estimating distributions than monthly. Thus we are interested in global precipitation datasets with daily or higher resolution. The larger sample size and range of precipitation rates resolved by daily data lead to more accurate representation of the distributions.

Section 2 introduces the datasets used in this study. Section 3 has the details of the statistics used to compare the precipitation estimates and how the distributions are computed. Section 4 evaluates the statistics and distributions, mostly on the example of North America, but other continental regions are mentioned to highlight stark differences or close similarities. Figures for all other continental regions are included in the supplementary material. Last, section 5 summarizes and discusses the implications of the results presented in this study.

\section{Datasets}

Table 1 lists all of the precipitation datasets considered in this study. The lowest native resolution of all precipitation datasets under consideration here is GPCP1DD, which has daily data on a $1^{\circ}$ grid. To facilitate comparisons of distributions and variability, all datasets were interpolated from their original grids to a grid with $1^{\circ}$ spatial and daily temporal resolution using conservative averaging. As temporal averaging is done to daily resolution, differences in the diurnal cycle phase and amplitude will not be resolved, so the resolved time scales that will be considered are daily to interannual. Since the seasonal cycle has a large effect on precipitation, all analyses are performed for each month of the year separately.

Our criteria (global data and daily resolution) exclude several well-established precipitation estimates from this study, for reasons related to either their temporal resolution or their regional coverage. These include PRISM (Daly et al. 1994), the North American Regional Reanalysis (Mesinger et al. 2006), stage IV radar data (Lin and Mitchell 2005), and Asian Precipitation-Highly Resolved Observational Data Integration Toward Evaluation of Water Resources (APHRODITE; Yatagai et al. 2012), because they are regional products, and the Global Precipitation Climatology Centre (GPCC; Becker et al. 2013), GPCP monthly estimates (Huffman et al. 1997), CPC Merged Analysis of Precipitation (CMAP; Xie and Arkin 1997), and CRU precipitation (Harris et al. 2014), because they are only monthly resolution.

\section{a. High-resolution precipitation products}

HRPPs aim to provide the best snapshot of precipitation estimates at high spatial and temporal resolution. Commonly, high-resolution IR brightness temperatures from geostationary satellites are related to precipitation rates using the more accurate PMW estimates from the 
TABLE 1. List of precipitation estimate datasets. Sources are geostationary infrared (Geo-IR), microwave (MW), gauges, or reanalyses. Only the main dataset reference is given for each dataset. Additional references and references with links to the actual datasets are included with the description of the datasets in section 2 .

\begin{tabular}{|c|c|c|c|c|}
\hline Name & Source & $\begin{array}{l}\text { Temporal coverage } \\
\text { and resolution }\end{array}$ & $\begin{array}{l}\text { Spatial coverage } \\
\text { and resolution }\end{array}$ & Reference \\
\hline TRMM3B42 & $\begin{array}{l}\text { Geo-IR; MW from SSM/I, } \\
\text { TMI, AMSU, and AMSR; } \\
\text { and gauges }\end{array}$ & 1998-2012, 3 hourly & $49^{\circ} \mathrm{S}-49^{\circ} \mathrm{N}, 0.25^{\circ}$ & Huffman et al. (2007) \\
\hline CMORPHv0.x & $\begin{array}{l}\text { Geo-IR and MW from SSM/I,TMI, } \\
\text { AMSU, and AMSR }\end{array}$ & 2003-2013, 3 hourly & $59^{\circ} \mathrm{S}-59^{\circ} \mathrm{N}, 0.25^{\circ}$ & Joyce et al. (2004) \\
\hline CMORPHCRTv1.0 & $\begin{array}{l}\text { Geo-IR and MW from SSM/I,TMI, } \\
\text { AMSU, and AMSR }\end{array}$ & 1998-2013, 3 hourly & $59^{\circ} \mathrm{S}-59^{\circ} \mathrm{N}, 0.25^{\circ}$ & Joyce et al. (2004) \\
\hline PERSIANN & Geo-IR and MW from TMI & 2001-13, 3 hourly & $59^{\circ} \mathrm{S}-59^{\circ} \mathrm{N}, 0.25^{\circ}$ & $\begin{array}{l}\text { Hsu et al. (1997) } \\
\text { Sorooshian et al. (2000) }\end{array}$ \\
\hline PERSICDRv1r1 & $\begin{array}{l}\text { Geo-IR; MW from TMI } \\
\text { (for training) SSM/I; IR; } \\
\text { and gauges }\end{array}$ & 1983-2013, daily & $60^{\circ} \mathrm{S}-60^{\circ} \mathrm{N}, 0.25^{\circ}$ & Ashouri et al. (2015) \\
\hline GPCP1DD & $\begin{array}{l}\text { Geo-IR; AVHRR low- } \\
\text { earth-orbit IR, SSM/I; } \\
\text { gauges; and TOVS } \\
\text { (poleward of } 40^{\circ} \mathrm{S}-40^{\circ} \mathrm{N} \text { ) }\end{array}$ & 1997-2013, daily & Global, $1^{\circ}$ & Huffman et al. (2001) \\
\hline GAUGE & Gauges & 1979-2005, daily & Global land, $0.5^{\circ}$ & $\begin{array}{l}\text { Xie et al. (2007); } \\
\text { Chen et al. (2008) }\end{array}$ \\
\hline GAUGERT & Gauges & 2006-13, daily & Global land, $0.5^{\circ}$ & $\begin{array}{l}\text { Xie et al. (2007); } \\
\text { Chen et al. (2008) }\end{array}$ \\
\hline JRA-55 & Reanalysis & 1979-2013, 3 hourly & $\begin{array}{l}\text { Global, Gaussian } \\
0.5625^{\circ} \text { grid }\end{array}$ & Kobayashi et al. (2015b) \\
\hline MERRA & Reanalysis & 1979-2013, hourly & Global, $0.5^{\circ} \times 2 / 3^{\circ}$ & Rienecker et al. (2011a) \\
\hline MERRA-2 & Reanalysis & 1980-2015, hourly & Global, $0.5^{\circ} \times 0.625^{\circ}$ & Bosilovich et al. (2015a) \\
\hline CFSR & Reanalysis & 1979-2010, 6 hourly & Global, $0.5^{\circ}$ & Saha et al. (2010a) \\
\hline ERAI & Reanalysis & 1979-2013, 3 hourly & Global, $0.75^{\circ}$ & Dee et al. (2011a) \\
\hline
\end{tabular}

polar-orbiting satellites. How these measurements are related, how the IR is calibrated, and whether the monthly means are scaled to match monthly rain gauge analyses varies between algorithms and constitutes the main sources of differences between the estimates; see Kidd and Huffman (2011) for an overview and an in-depth description of the various techniques. In general, PMW gives a more accurate estimate than IR, because this is a more direct observation of precipitation. But this advantage deteriorates for time averages due to the lower sampling frequency of PMW compared to IR. The combination of PMW and IR measurements includes the different errors inherent in each technique (Kidd and Huffman 2011). We note that there are versions of these precipitation products with higher resolutions than used here. While a higher resolution would likely improve the results due to better sampling, it would not be advantageous for the comparisons presented here, because all datasets have been interpolated to match the lowest-resolution dataset available.

The Climate Prediction Center morphing method (CMORPHv0.x; Joyce et al. 2004; Joyce and Janowiak 2005) estimates rainfall by combining IR and PMW measurements. High-quality PMW rainfall estimates are propagated (using linear interpolation in time) by motion vectors derived from high-frequency IR imagery. CMORPH is available from 2003 to the present at 3-hourly intervals on a $0.25^{\circ}$ grid from $60^{\circ} \mathrm{S}$ to $60^{\circ} \mathrm{N}$. A bias-corrected version (CMORPHCRTv1.0; Joyce et al. 2004; CMORPHv1.0 2015) is also available on the same grid, from 1998 to 2015. CMORPHCRTv1.0 uses a consistent algorithm and is bias corrected against a rain gauge analysis over land and GPCP pentad data over the ocean. Correction over land is done by matching probability density functions against daily gauge analysis using optimal interpolation with orographic correction. The bias correction results in a reduction of the spurious trends seen in CMORPH. For better visualization, results are shown for CMORPHCRTv1.0 only and results for CMORPH are mentioned where appropriate. Both products are also available at a resolution of $8 \mathrm{~km}$ and $30 \mathrm{~min}$, but the higher resolution is not necessary for the analysis presented here.

The Tropical Rainfall Measuring Mission 3B42v7 (TRMM3B42) product provides 3-hourly precipitation estimates on a $0.25^{\circ}$ grid between $50^{\circ} \mathrm{S}$ and $50^{\circ} \mathrm{N}$ and from 1998 to the present. The monthly means of the 3-hourly 
microwave-calibrated IR rainfall estimates are combined with the GPCC monthly rain gauge analysis to generate a monthly satellite-gauge combination (TRMM3B43). Each 3-hourly field is then scaled to sum to the corresponding monthly satellite-gauge field. Like all satellite precipitation estimates, TRMM3B42 was previously determined to have large relative errors at small precipitation rates; however, time/area averaging significantly reduces the random error (Huffman et al. 2007, 2012).

The Precipitation Estimation from Remotely Sensed Information using Artificial Neural Networks (PERSIANN) precipitation estimates are based on IR from geostationary satellites. In addition, PMW measurements from the TRMM satellite are used to update the artificial neural network algorithm parameters (Hsu et al. 1997; Sorooshian et al. 2000; Braithwaite 2000). PERSIANN is available from 2001-present at 3-hourly intervals on a $0.25^{\circ}$ grid from $50^{\circ} \mathrm{S}$ to $50^{\circ} \mathrm{N}$.

\section{b. Climate data records of precipitation}

For climate data records (CDRs) homogeneity is emphasized over instantaneous accuracy. The Climate Prediction Center rain gauge (GAUGE) dataset is based on quality-controlled station data from more than 30000 stations. These data are then interpolated to create analyzed fields of daily precipitation with bias correction for orographic effects (Xie et al. 2007). Note that daily gauge data typically have different ending times in different regions and that daily readings tend to be in the morning. The global analysis is available daily on a $0.5^{\circ}$ grid from 1979 to 2005 (Xie et al. 2007; Chen et al. 2008; Xie 2009). The real-time version of the CPC gauge dataset (GAUGERT) uses about 17000 stations and is available on the same grid at the same time resolution from 2005 to the present. Large-scale averages of long-term means and variances are comparable between GAUGE and GAUGERT. Additional stations used in the GAUGE estimate are generally located in regions of dense observing networks. In regions with sparse observations the number of stations stays about the same from GAUGE to GAUGERT. Because of this GAUGE and GAUGERT estimates are combined by extending the GAUGE data with the GAUGERT data and the resulting dataset is referred to as GAUGE+RT.

Global Precipitation Climatology Project daily, $1^{\circ}$ precipitation (GPCP1DDv1.2) estimates between $40^{\circ} \mathrm{S}$ and $40^{\circ} \mathrm{N}$ are computed based on the thresholdmatched precipitation index (TMPI; Huffman et al. 2001). Outside of that, the developers use an adjusted Susskind TOVS/AIRS cloud volume proxy (Susskind et al. 1997). For the TMPI, IR temperatures are compared to a threshold, and all cold pixels are given the same conditional precipitation rate, with threshold and conditional precipitation rate set locally by month. GPCP1DD monthly means are normalized to match the monthly GPCP satellite-gauge precipitation estimate version 2.2 (Adler et al. 2003), which is based on satellite data and rain gauge analysis from the GPCC. The GPCC monthly rain gauge analysis is bias corrected to account for systematic errors due to wetting, evaporation, and aerodynamic effects (Huffman et al. 1997), similarly to what was described above for the CPC rain gauge analysis. The GPCP1DDv1.2 precipitation estimates are available on a global grid from 1996 to October 2015 (Bolvin 2001).

One of the newest CDRs is the Precipitation Estimation from Remotely Sensed Information using Artificial Neural Networks-Climate Data Record (PERSICDRv1r1; Ashouri et al. 2015; Sorooshian et al. 2014). This is generated using the PERSIANN algorithm, and adjusted using the GPCP monthly product to match monthly precipitation rates on a $2.5^{\circ}$ grid between the two products. In contrast to the HRPP PERSIANN, the PERSICDRv1r1 model is pretrained on stage IV hourly precipitation data and the model parameters are then kept fixed for the full historical record of IR data. PERSICDRv1r1 is available on a $0.25^{\circ}$ grid between $50^{\circ} \mathrm{S}$ and $50^{\circ} \mathrm{N}$ and from 1983 to the present day.

\section{c. Reanalysis precipitation products}

Another way to estimate global precipitation is through short-term forecasts provided by global reanalyses. The underlying models assimilate a wide variety of observations, but in general not precipitation measurements or analyses. Precipitation is usually provided by a prior short-range forecast, and this inherits the systematic errors of the forecast model. The advantage to reanalyses is that all variables are dynamically consistent to some extent. However, as precipitation data are not typically constrained by the analysis procedure, reanalyzed precipitation is highly model dependent (Trenberth et al. 2011). This is particularly true in the tropics and over continents during the summer, when convective precipitation dominates. These issues are compounded by the well-known problem in general circulation models (GCMs) of an overabundance of light rainfall and too infrequent extreme precipitation (e.g., Trenberth et al. 2003; Wilcox and Donner 2007; Stephens et al. 2010). As global reanalyses are based on similar GCMs they tend to have the same shortcomings in this respect. One exception is the North American Regional Reanalysis (Mesinger et al. 2006), which does assimilate precipitation. There is evidence that assimilation of precipitation can improve precipitation estimates and the atmospheric moisture budget (Ruane 2010a,b; 
TABLE 2. Description of the metrics used in the analysis. The variable $P(x, y, d, m, \mathrm{yr})$ represents precipitation at longitude $x$, latitude $y$, day $d$, month $m$, and year yr. Here $N_{m}$ is the total number of days in month $m, m=1, \ldots, 12 ; N_{A}$ is the number of grid points in region $A$ with $\left(x_{i}, y_{j}\right) \in A ; w_{j}$ are the weights that account for changing area of the grid box with latitude; $P_{1}, \ldots, P_{N_{d}}$ are the different datasets, with $N_{d}$ the total number of datasets; and $M$ is the mean of all the precipitation datasets.

\begin{tabular}{ll}
\hline \hline \multicolumn{1}{c}{ Metric } & $\bar{P}(x, y, m)=\frac{1}{N_{m}} \sum_{\mathrm{yr}=1}^{N} \sum_{k=1}^{N_{m y}} P\left(x, y, d_{k}, m, \mathrm{yr}\right)$ \\
\hline Monthly mean & $\sigma^{2}(x, y, m)=\frac{1}{N_{m}} \sum_{\mathrm{yr}=1}^{N} \sum_{k=1}^{N_{m y}}\left[P\left(x, y, d_{k}, m, \mathrm{yr}\right)-\bar{P}(x, y, m)\right]^{2}$ \\
Monthly variance & $D(x, y, m)=\bar{P}(x, y, m)-\bar{Q}(x, y, m)$ \\
Difference & $D(x, y, m)=\frac{\bar{P}(x, y, m)-\bar{Q}(x, y, m)}{\bar{P}(x, y, m)} \times 100$ \\
Percentage difference & $P_{A}(d, m, \mathrm{yr})=\frac{1}{N_{A}} \sum_{i=1}^{N_{x A}} \sum_{j=1}^{N_{y A}} w_{j} P\left(x_{i}, y_{j}, d, m, \mathrm{yr}\right)$ \\
Spatial average & $\sigma_{P}(x, y)=\frac{1}{N_{t}} \sum_{k=1}^{N_{t}} \sqrt{\frac{1}{N_{d}} \sum_{d=1}^{N_{d}}\left[P_{d}\left(x, y, t_{k}\right)-M\left(x, y, t_{k}\right)\right]^{2}}$ \\
\hline
\end{tabular}

Kennedy et al. 2011) and the forecast of other variables (Lien et al. 2016).

The decrease of precipitation variability with spatial averaging implies that to facilitate comparison of reanalyses with the other precipitation estimates, the reanalyses must be generated at a resolution the same as or higher than that of the other estimates. Lower-resolution reanalyses previously have been found to have lower rain rates and a smaller range of resolved rain rates overall when compared to satellite- or gauge-based estimates, similar to operational forecast models (Janowiak et al. 2010). This is valid even when area averaging (and thus decreasing the variability of) the observational estimates to the same resolution as the reanalyses. We obtained similar results when applying our analysis to lower-resolution reanalyses. Here we consider the most recent global reanalysis products that have a spatial resolution of smaller than $1^{\circ}$. These are the European Centre for MediumRange Weather Forecasts (ECMWF) interim reanalysis (ERA-Interim, hereinafter ERAI; Dee et al. 2011a,b), the Modern-Era Retrospective Analysis for Research and Applications (MERRA; Rienecker et al. 2011a,b), MERRA version 2 (MERRA-2; Bosilovich et al. 2015a,b), the NCEP Climate Forecast System Reanalysis (CFSR; Saha et al. 2010a,b), and the Japanese 55-year Reanalysis (JRA-55; Kobayashi et al. 2015a,b).

TABLE 3. Description of continental regions used in the analysis. Only points over land inside the domains are used. Also shown are the amplitude (mm day ${ }^{-1}$ ) of the area-averaged mean annual cycle for 2001-12 and the phase (the day of the year the maximum occurs). The annual cycle is defined as the first four harmonics of the mean daily annual cycle. These are given for all datasets in the order (TRMM3B42, GPCP1DD, CMORPHCRTv1.0, PERSIANN, PERSICDRv1r1, GAUGE+RT, JRA-55, MERRA-2, CFSR, ERAI). The minimum and maximum are highlighted in boldface.

\begin{tabular}{|c|c|c|c|}
\hline Region & Lat, lon & Amplitude & Phase \\
\hline North America & $15^{\circ}-49^{\circ} \mathrm{N}, 165^{\circ}-50^{\circ} \mathrm{W}$ & $\begin{array}{c}(1.47,1.19,1.22,1.22,1.19 \\
\quad 1.38, \mathbf{1 . 5}, 1.33,1.37, \mathbf{1 . 1 6})\end{array}$ & $(270,273, \mathbf{2 7 6}, 256,271, \mathbf{2 5 3}, 266,264,272,272)$ \\
\hline South America & $49^{\circ} \mathrm{S}-15^{\circ} \mathrm{N}, 90^{\circ}-30^{\circ} \mathrm{W}$ & $\begin{array}{r}(1.26,1.25,1.08,1.57,1.25 \\
\mathbf{3 . 3 5}, 1.2,1.4,1.51, \mathbf{1 . 0 1})\end{array}$ & $(75,73,73, \mathbf{3 0 4}, 71,59,328, \mathbf{9 1}, 84,340)$ \\
\hline Europe & $30^{\circ}-49^{\circ} \mathrm{N}, 15^{\circ} \mathrm{W}-50^{\circ} \mathrm{E}$ & $\begin{array}{c}(1.62,1.51,1.12, \mathbf{0 . 4 5}, 1.47 \\
0.771 .21,1.27, \mathbf{1 . 6 9}, 1.02)\end{array}$ & $(321,336,310, \mathbf{2 9 8}, 339,321,328,331, \mathbf{3 4 4}, 330)$ \\
\hline Africa & $35^{\circ} \mathrm{S}-30^{\circ} \mathrm{N}, 20^{\circ} \mathrm{W}-50^{\circ} \mathrm{E}$ & $\begin{array}{l}(0.67,0.57, \mathbf{0 . 5 6}, \mathbf{0 . 8 8}, 0.6 \\
\quad 0.79,0.77, \mathbf{0 . 8 8}, 0.61,0.74)\end{array}$ & $(92, \mathbf{8 7}, 96,93,88, \mathbf{2 2 8}, \mathbf{8 7}, 93,92,89)$ \\
\hline Asia & $5^{\circ}-49^{\circ} \mathrm{N}, 50^{\circ}-150^{\circ} \mathrm{E}$ & $\begin{array}{l}(4.09,3.78,3.54,3.8,3.87 \\
\quad \mathbf{2 . 9 9}, \mathbf{5 . 1 2}, 4.99,4.39,3.38)\end{array}$ & $(204,203,206, \mathbf{1 9 6}, 202,202,204, \mathbf{2 0 7}, 203, \mathbf{2 0 7})$ \\
\hline Maritime Continent & $10^{\circ} \mathrm{S}-5^{\circ} \mathrm{N}, 90^{\circ}-165^{\circ} \mathrm{E}$ & $\begin{array}{c}(3.19, \mathbf{3}, 3.13,4.56,3.03,3.21) \\
4.39,4.43, \mathbf{5 . 1 5}, 3.64\end{array}$ & $(364,4,365,18,5, \mathbf{3 5 4}, 363,366, \mathbf{1 9}, 2)$ \\
\hline Australia & $49^{\circ}-10^{\circ} \mathrm{S}, 110^{\circ}-155^{\circ} \mathrm{E}$ & $\begin{array}{c}(3.05,2.84,2.89, \mathbf{4 . 0 2}, 2.88 \\
\quad 3.06,3.52,3.46,2.41, \mathbf{2 . 0 4})\end{array}$ & $(42,43,41, \mathbf{3 4}, 43,41,40,42,43, \mathbf{4 6})$ \\
\hline
\end{tabular}



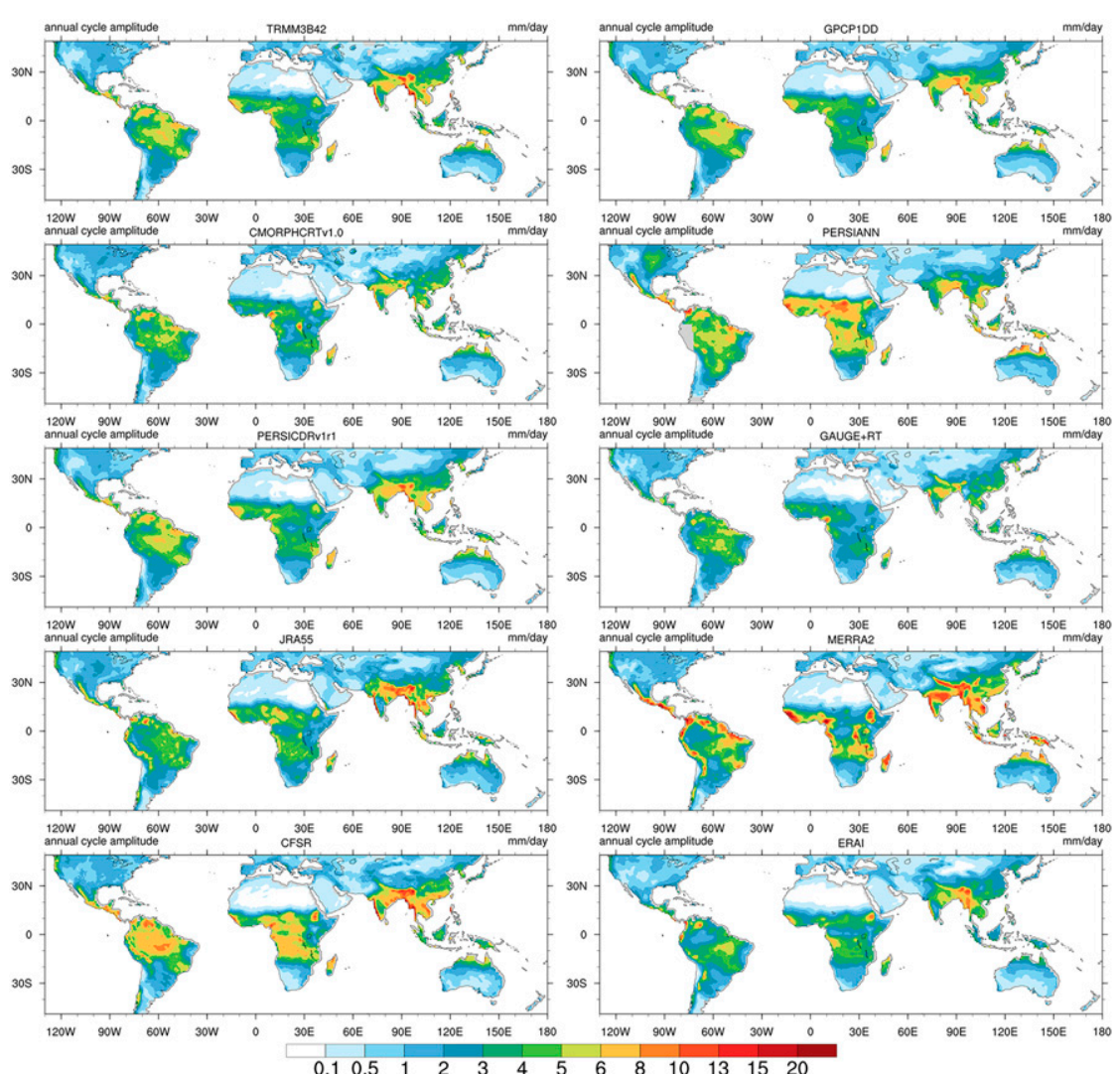

FIG. 1. Annual cycle amplitude $\left(\mathrm{mm} \mathrm{day}^{-1}\right)$ for the 10 datasets at $1^{\circ}$ daily resolution for 2001-12. The annual cycle is computed as the first four harmonics of the mean daily seasonal cycle. The amplitude is half of the difference between the minimum and maximum of the annual cycle.

\section{d. Caveat on independence of precipitation estimates}

None of the above precipitation estimates is independent of all the others, for there is a large degree of overlap in the source data that goes into the different estimates (Table 1). PERSIANN and CMORPH are the only satellite products without routine inclusion of gauge data. Both TRMM3B42 and GPCP1DD use the same monthly satellite-gauge combination algorithm (Huffman et al. 1997) to constrain their monthly totals. As mentioned above, the GAUGE and GAUGERT estimates are for nonoverlapping time periods and use a different total number of stations, but the underlying algorithm is the same. Their statistics compare very well even though only about half the number of stations are available for the realtime product GAUGERT (17000 compared to 30000 for the retrospective GAUGE analysis).

\section{Methods}

The first step, before any other analysis is done, is to interpolate all datasets from their original grids to a coarser grid with $1^{\circ}$ spatial and daily temporal resolution using conservative averaging. All computations shown in this study are done on the regridded datasets in an attempt to minimize the impacts of differing resolution on the results.

The methods used to evaluate the precipitation estimates include basic statistical quantities such as means and variances, and the differences among estimates at each grid point (Table 2). We also show the mean and variance differences as percentage of the mean and variance respectively to compare their relative sizes. In addition we consider temporal averages on time scales of a week, a month, and a year. Spatial averages are always area averages, taking into account the change in grid area with latitude.

Frequency distributions of precipitation are highly skewed, with the smallest rain rates being the most frequent (e.g., Sardeshmukh et al. 2015). In general this makes comparing different distributions difficult, because the tails tend to be undersampled. One way to reduce the discrepancy between the number of samples in the lower 

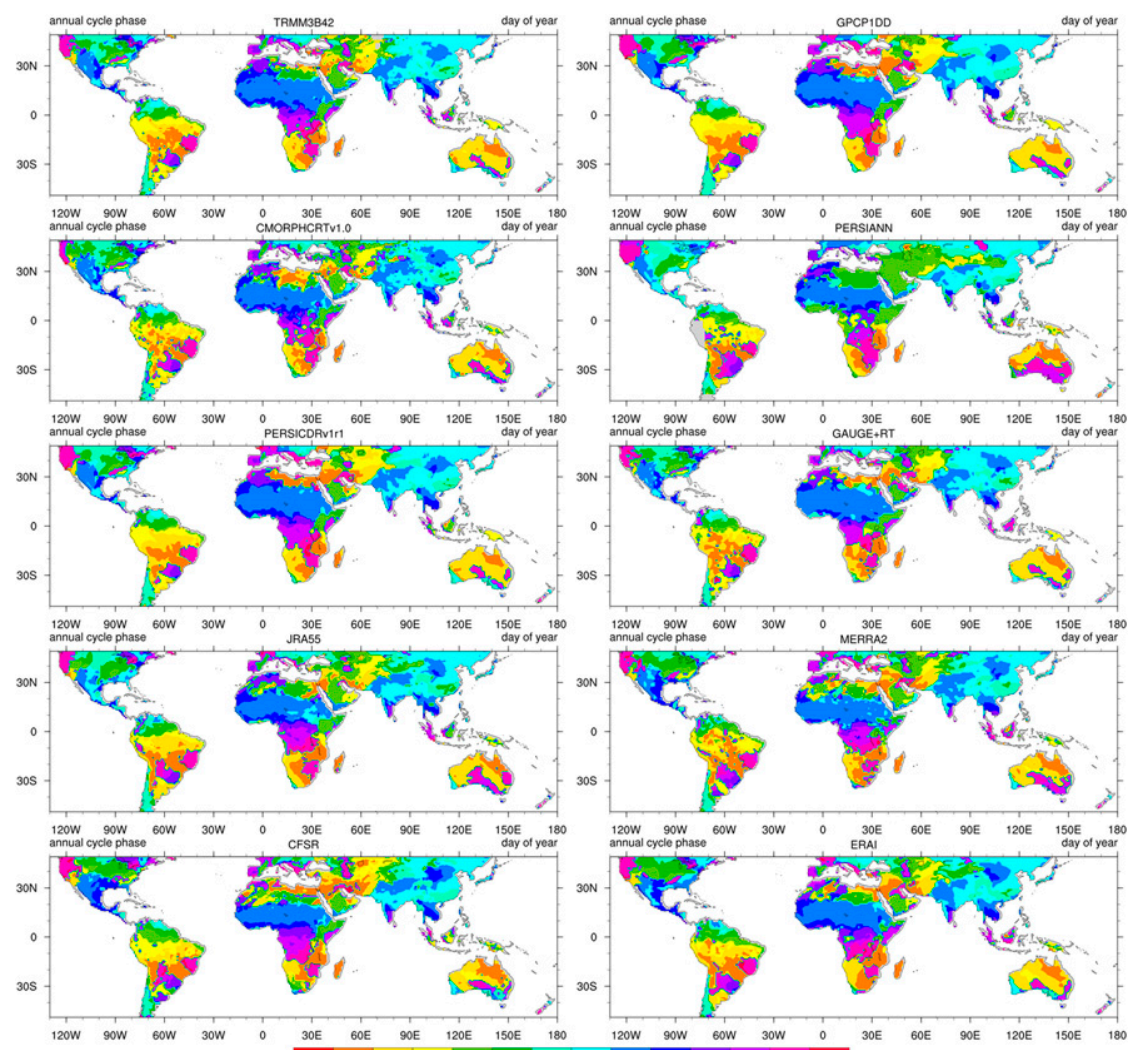

$1 \quad 316191121151181211241271301331361$

FIG. 2. Annual cycle phase in day of year for the 10 datasets at $1^{\circ}$ daily resolution for 2001-12. The annual cycle is computed as the first four harmonics of the mean daily seasonal cycle. The phase is the day of the year the maximum of the annual cycle is achieved.

rain rate bins and the higher rain rate bins is to use logarithmic bin sizes that increase with rain rate. In addition to frequency distributions of precipitation rate we also compare rain amount by rain rate distributions. The integral under these curves is equal to the total precipitation amount. These distributions tend to be skewed toward lower precipitation rates with the largest amounts occurring at intermediate rain rates. For both types of distributions a logarithmic bin size is used. The number of bins is 100 with a constant logarithmic (base 10) bin length. Setting the minimum bin to $10^{-4}$ and the maximum to $10 \mathrm{~mm} \mathrm{~h}^{-1}$, the bin length then becomes $\Delta b=$ $\left(\log _{10} 10-\log _{10} 10^{-4}\right) / 100=0.05$. The edges of the bins are computed according to $b_{i}=10^{-4} 10^{i \Delta b}, i=0, \ldots, 100$, which results in increasing bin sizes with precipitation rate. Rain rates below the minimum (including zero rain rates) are counted in the lowest bin. Experiments with changing the minimum bin to $10^{-3}$ and $10^{-2}$ show that the bulk of the distribution is not very sensitive to the lower bound.

Global maps of the spread among precipitation datasets (Table 2) can be used to identify regions with more or less variability among the datasets. First the mean seasonal cycle is removed from each dataset. The spread is then computed as the standard deviation among datasets at each grid point and time, which is then averaged for each month of the year.

\section{Results}

The continental regions used in the analyses are defined as the land areas contained within the latitudelongitude areas given in Table 3. All results presented are for data interpolated to match GPCP1DD.

\section{a. Annual cycle}

A summary of the annual cycle is given in Figs. 1 and 2 in the form of its amplitude and phase. The annual cycle is defined as the first four harmonics of the mean daily seasonal cycle. Differences in the amplitude are large over equatorial Africa and South America, and the Indian monsoon region. Over North America the amplitude of the annual cycle in the Midwest United States ranges from 3 to $13 \mathrm{~mm}$ day $^{-1}$. The phase is defined as 

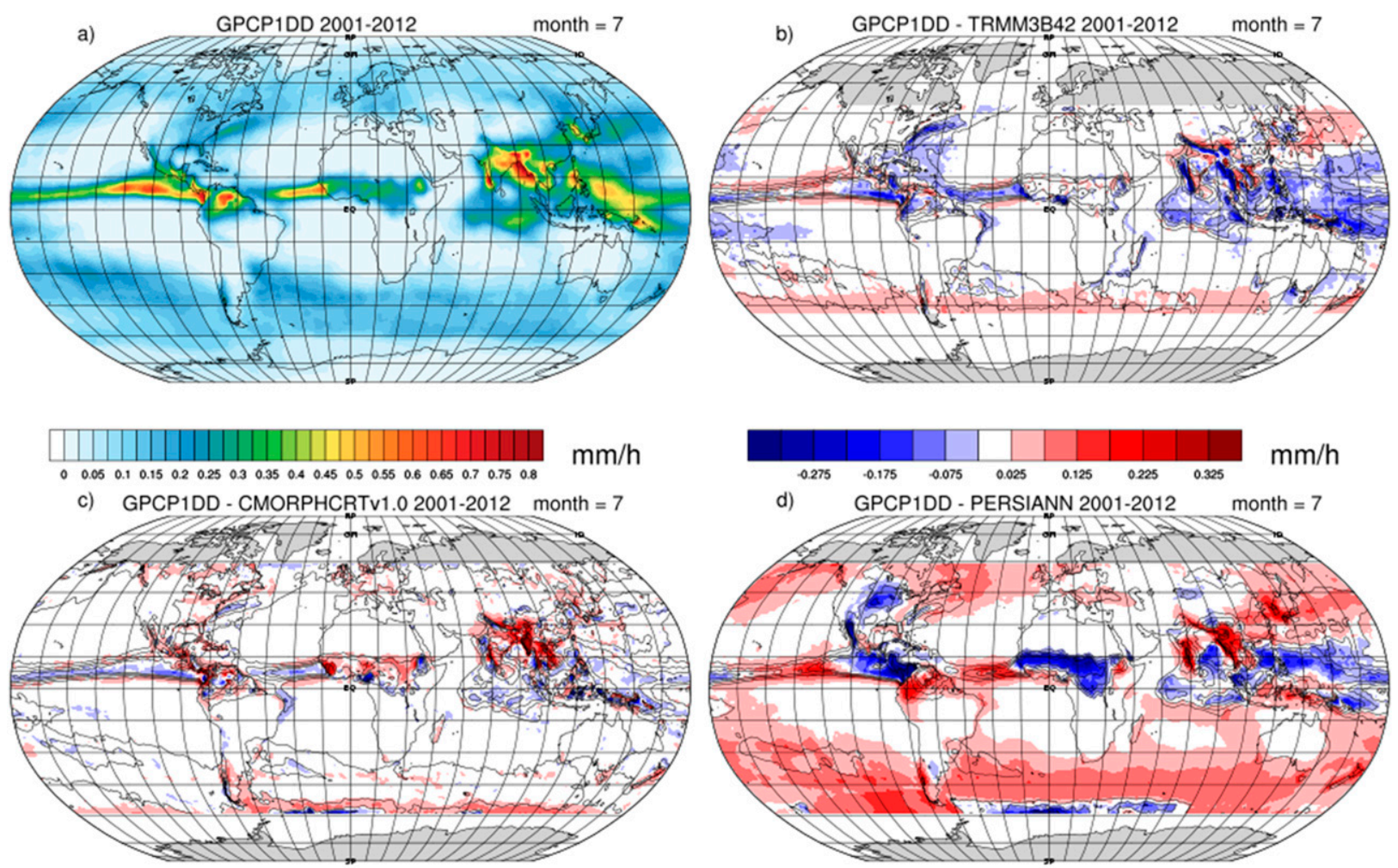

e) GPCP1DD - GAUGE + RT 2001-2012 month $=7$
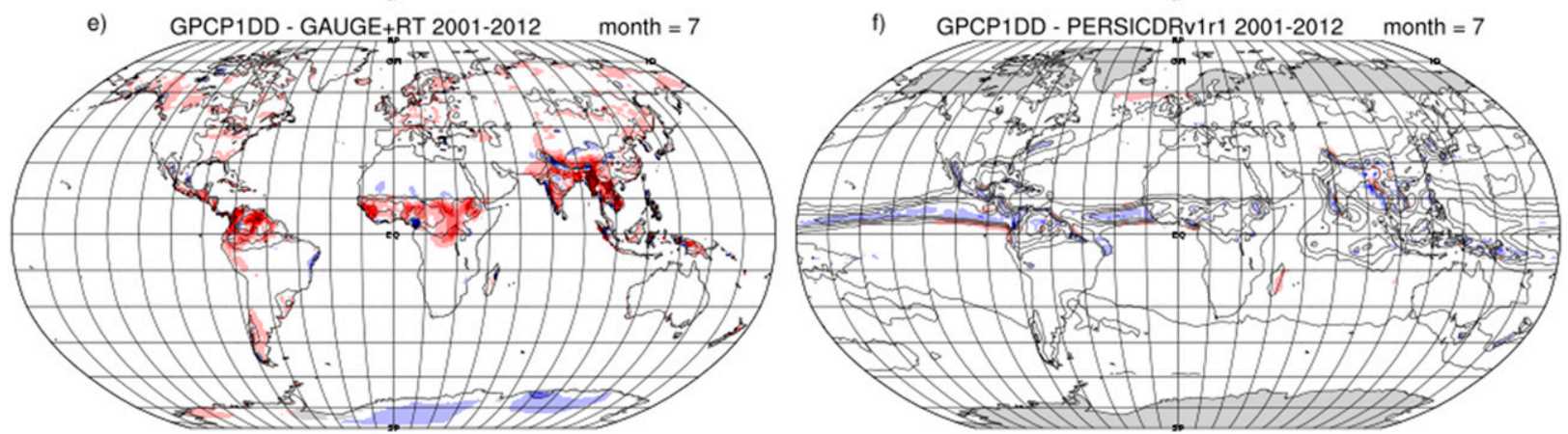

FIG. 3. Monthly long-term means of precipitation for July: (a) mean for GPCP1DD and (b)-(f) the difference between GPCP1DD mean and the respective dataset mean for the period is indicated in shading; contours show the mean monthly precipitation for the respective dataset. Contour interval is from 0 to 0.4 by $0.1 \mathrm{~mm} \mathrm{~h}^{-1}$. All datasets are at $1^{\circ}$ daily resolution.

the day of the year the annual cycle is maximized, and so does not take into account if a location has multiple maxima in precipitation during the year. This is potentially an issue in equatorial South America and Africa, although overall the timing of the reported annual maxima in precipitation is captured consistently among the estimates. Regions with large discrepancies in timing are northern Africa, parts of Australia (both regions where the annual cycle amplitude is very small), and the northwestern United States (Fig. 2).

\section{b. Differences in means and variances}

To compare patterns of monthly means and variances it was convenient to choose one of the datasets to compare with the others. We chose GPCP1DD, not because it is the most accurate daily precipitation estimate, but because it is widely used and readers may have more familiarity with this than other datasets. GPCP1DD also has the most extensive time coverage except for PERSICDRv1r1, which is a newer product. In addition, GPCP1DD is the only precipitation estimate that is truly global.

Distinctive differences among datasets of largescale patterns of means and variances can be identified. The climatological mean monthly precipitation for July is shown in Fig. 3. Comparison of the mean monthly precipitation across datasets shows large variability (Figs. 3b-d), especially in areas such as the 

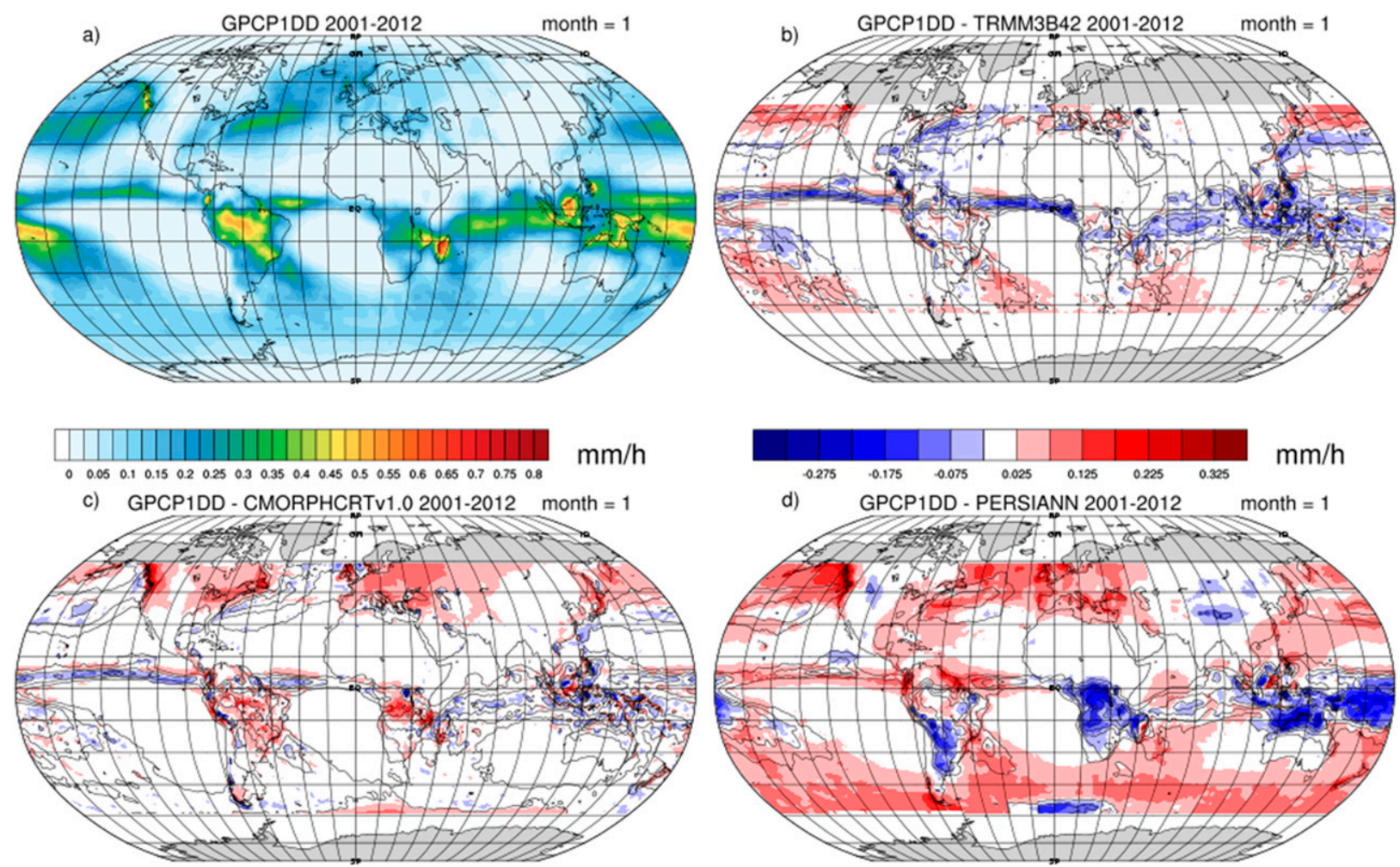

e) GPCP1DD - GAUGE + RT 2001-2012 month $=1$
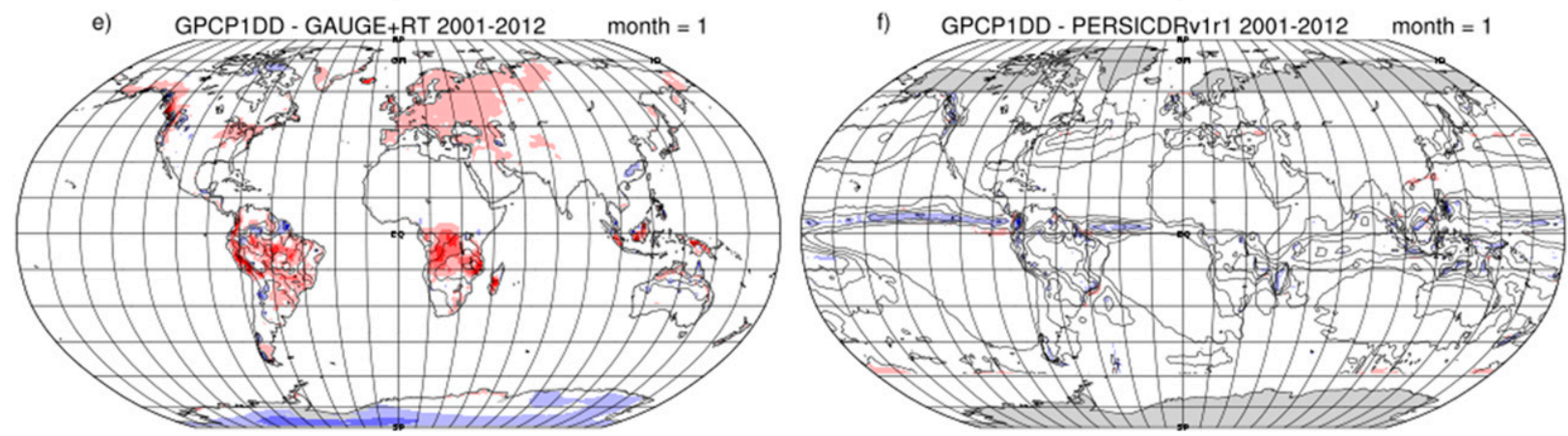

FIG. 4. As in Fig. 3, but for January.

intertropical convergence zone (ITCZ). Other regions with large differences in the means are continental areas in the summer hemisphere and the western boundary ocean current regions. Because of large spatial gradients in some regions, small variations in the location of climatological features like the ITCZ can lead to large local differences in mean precipitation.

Figures $3 \mathrm{c}, \mathrm{d}$ and $4 \mathrm{c}, \mathrm{d}$ show that GPCP1DD mean precipitation exceeds mean precipitation from the satellite-only product PERSIANN especially over the oceans, except in regions with intense convective precipitation. The bias-corrected CMORPHCRTv1.0 has small differences from GPCP1DD comparable to GAUGE+RT. In particular, CMORPHCRTv1.0 exceeds GPCP1DD over tropical oceans, and GPCP1DD exceeds CMORPHCRTv1.0 over tropical land areas and over the midlatitudes in winter. As is to be expected based on previous work, TRMM3B42 and GPCP1DD match well over land, but TRMM3B42 commonly has higher means over tropical oceans and smaller means over midlatitude ocean areas (Fig. 3b). The closest match is between GPCP1DD and PERSICDRv1r1 monthly means (Fig. 3f), where any differences are below $0.075 \mathrm{~mm}$ day $^{-1}$. This is to be expected based on the construction method used in GPCP1DD and PERSICDRv1r1. The satellite-only product PERSIANN has higher means over summertime continental regions than the gauge corrected estimates. Over land the main bias for gauge-corrected precipitation estimates 

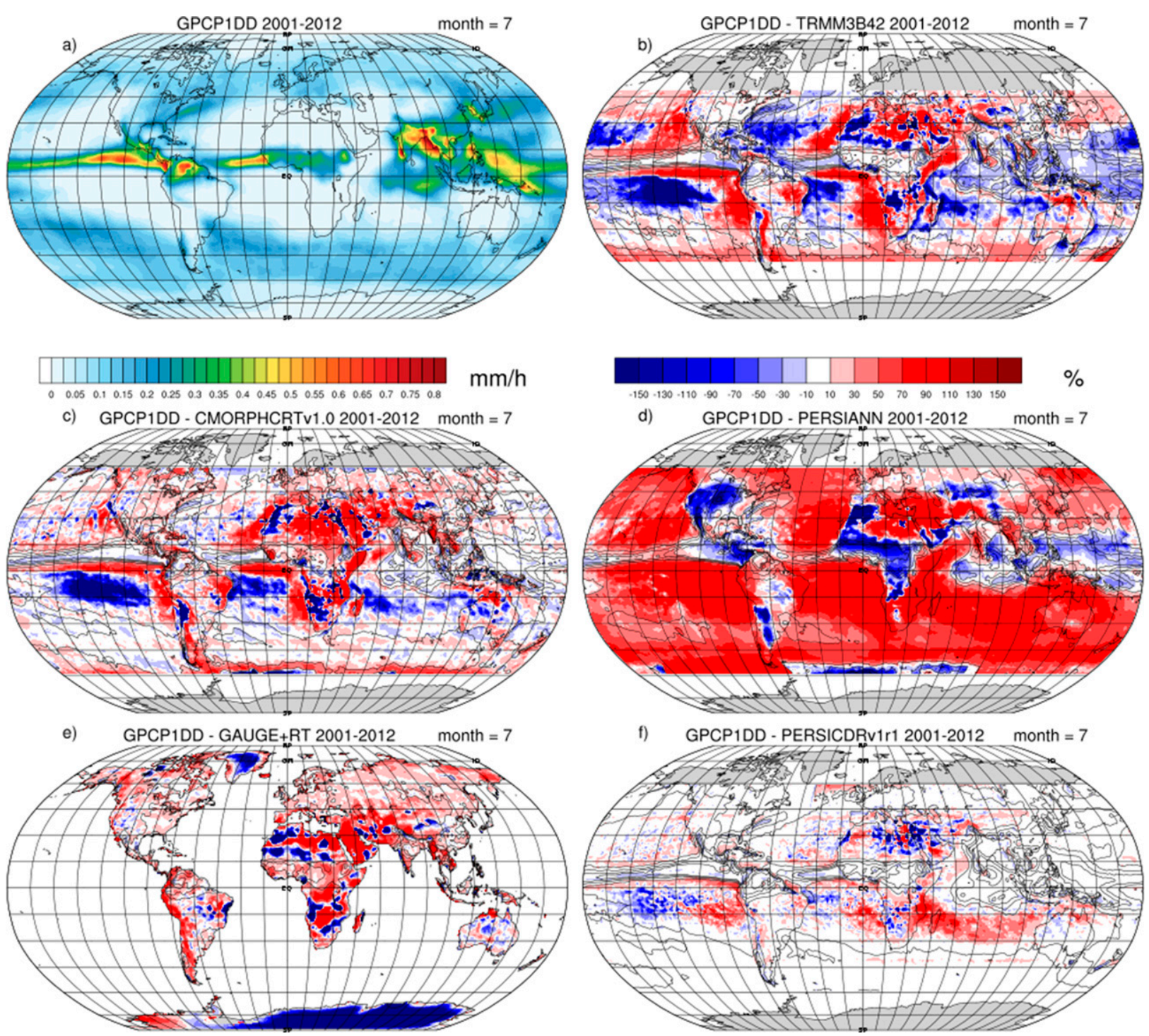

FIG. 5. Monthly long-term means of precipitation and percentage difference for July. (a) Mean for GPCP1DD. (b)-(f) The percentage difference between GPCP1DD mean and the respective dataset mean for the period is indicated in shading; contours show the mean monthly precipitation for the respective dataset. Contour interval as in Fig. 3. All datasets are at $1^{\circ}$ daily resolution.

is due to the bias in the rain gauge analysis used. This is visible in the differences between GPCP1DD monthly means and GAUGE + RT monthly means (Figs. 3e and $4 \mathrm{e}$ ), where the rain gauge analysis that contributes to GPCP1DD is bias corrected for losses due to wetting, evaporation, or aerodynamic effects, and the CPC GAUGE+RT analysis is corrected for orographic effects. Comparing the July estimates to January it becomes clear that PERSIANN tends to underestimate winter precipitation over continents and overestimate summer precipitation when compared to GPCP1DD. GAUGE + RT estimates are biased low on average, but not everywhere compared to GPCP1DD, and TRMM3B42 typically exceeds GPCP1DD in regions of vigorous convection.

Percentage differences of the monthly means (Fig. 5) show clearly that the differences in the means are often as large as the means. This is especially true in areas with small mean values like the subtropical dry zones, where small differences translate into large percentage differences. Depending on the dataset under consideration, this can also be the case in regions with large mean precipitation and large variability like the continental United States in the summer and the edge of the ITCZ (e.g., GPCP1DD and PERSIANN; Fig. 5d). 

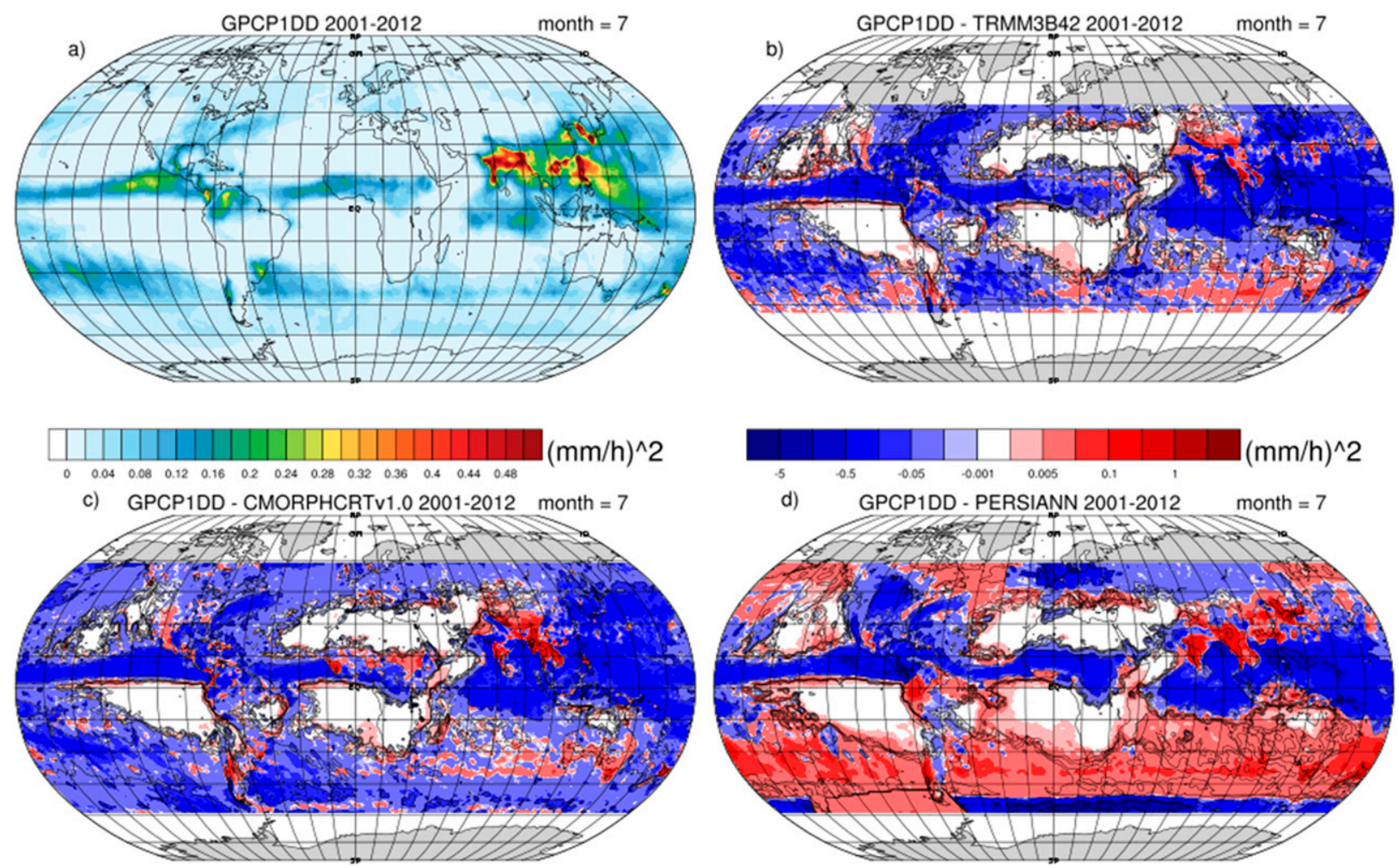

e) GPCP1DD - GAUGE+RT 2001-2012 month $=7$
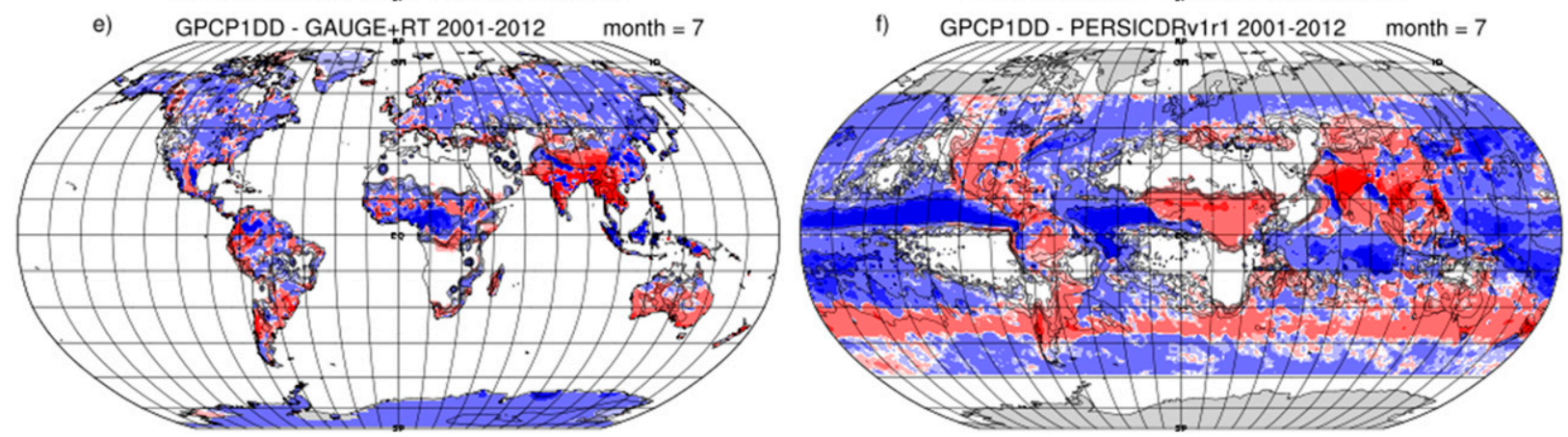

FIG. 6. Monthly mean variance of precipitation for July. (a) Mean variance for GPCP1DD. (b)-f) The difference between the GPCP1DD mean variance and the respective dataset mean variance for the period is indicated in shading; contours show the mean monthly precipitation variance for the respective dataset. Contour intervals are $0.001,0.002,0.005,0.01,0.1,1,2,10\left(\mathrm{~mm} \mathrm{~h}^{-1}\right)^{2} . \mathrm{All}^{2}$ datasets are at $1^{\circ}$ daily resolution.

Monthly mean daily precipitation variance is large where mean precipitation is large (Figs. 3a and 6a). The largest variances are in areas with highly variable convective precipitation such as the ITCZ, the Indian Ocean, and the Indian monsoon region. TRMM3B42 and CMORPHCRTv1.0 have the largest variance on average (Figs. 6b,c), and differences in variances are as large as the variance for most areas of the globe (not shown). This holds even for areas with large variability, like the ITCZ. That magnitudes of spread and mean should correlate is to be expected for a positive definite quantity like precipitation, but the magnitude of the difference in variance among datasets is notable. The combined rain gauge dataset GAUGE+RT shows smaller variance than GPCP1DD (Figs. 6e and 7e) over boreal winter land areas and the opposite during boreal summer. Results are more mixed over South America, Africa, and Australia. PERSICDRv1r1 variance is smaller than GPCP1DD variance over land, but exceeds GPCP1DD variance over the ocean. Note, however, that differences in variance are smaller between PERSICDRv1r1 and GPCP1DD than for any other dataset (Figs. 6f and 7f). While small differences between the means of PERSICDRv1r1 and GPCP1DD are to be expected, that does not hold for daily variance. While CMORPHCRTv1.0 has the larger variance for most regions, Figs. $6 \mathrm{c}$ and 

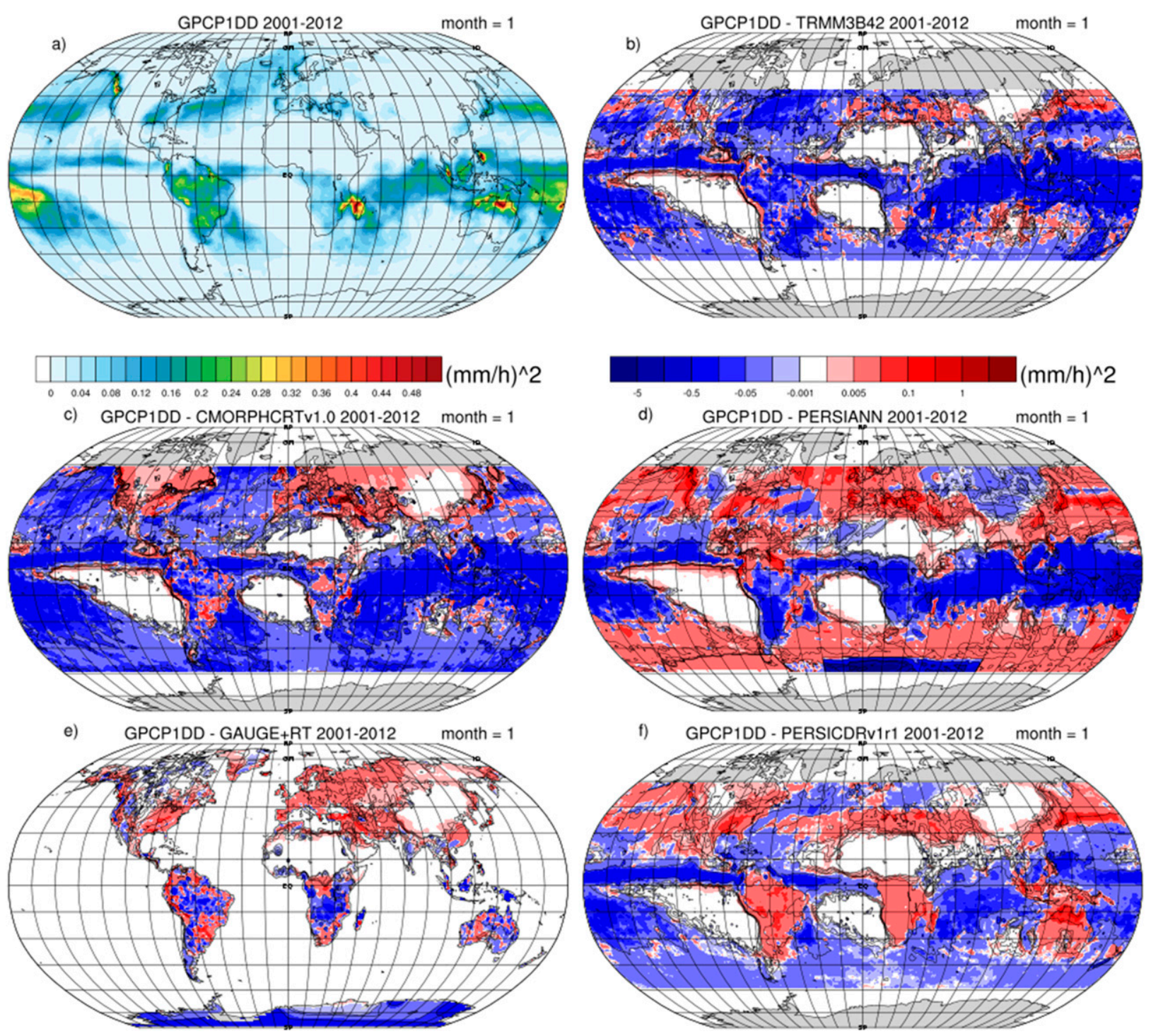

FIG. 7. As in Fig. 6, but for January.

7c show that GPCP1DD variance is higher in the winter hemisphere.

\section{c. Time series}

Next, we examine time series mainly at the continental scale for North America, where there is a relatively dense observing network and so the potential for constraining estimates is high. Time series averaged over North America are also a good example in that they illustrate many of the issues also observed in other regions. Other regions (Table 3) are mentioned where notable, but these results are not shown. Figures for all other regions are included in the supplementary material. Figure 8 and Table 3 also include the amplitude and phase of the mean seasonal cycle averaged over each continental region. The minimum and maximum amplitude estimated by the different products in general differ by a factor of $1.5-3$. The timing of the seasonal cycle is estimated to be within 30 days of each other for North America, Asia, Australia, and the Maritime Continent, but for Europe the estimates differ by 46 days. Note that the outliers for the timing are not necessarily from the reanalyses. For North America GAUGE+RT and for Europe PERSIANN both place the maxima of the annual cycle earlier in the year than the other estimates. South America and Africa have two maxima in the seasonal cycle, and there is disagreement among datasets on which of these dominates.

The temporal evolution of global land-averaged precipitation rates on annual and monthly time scales is 

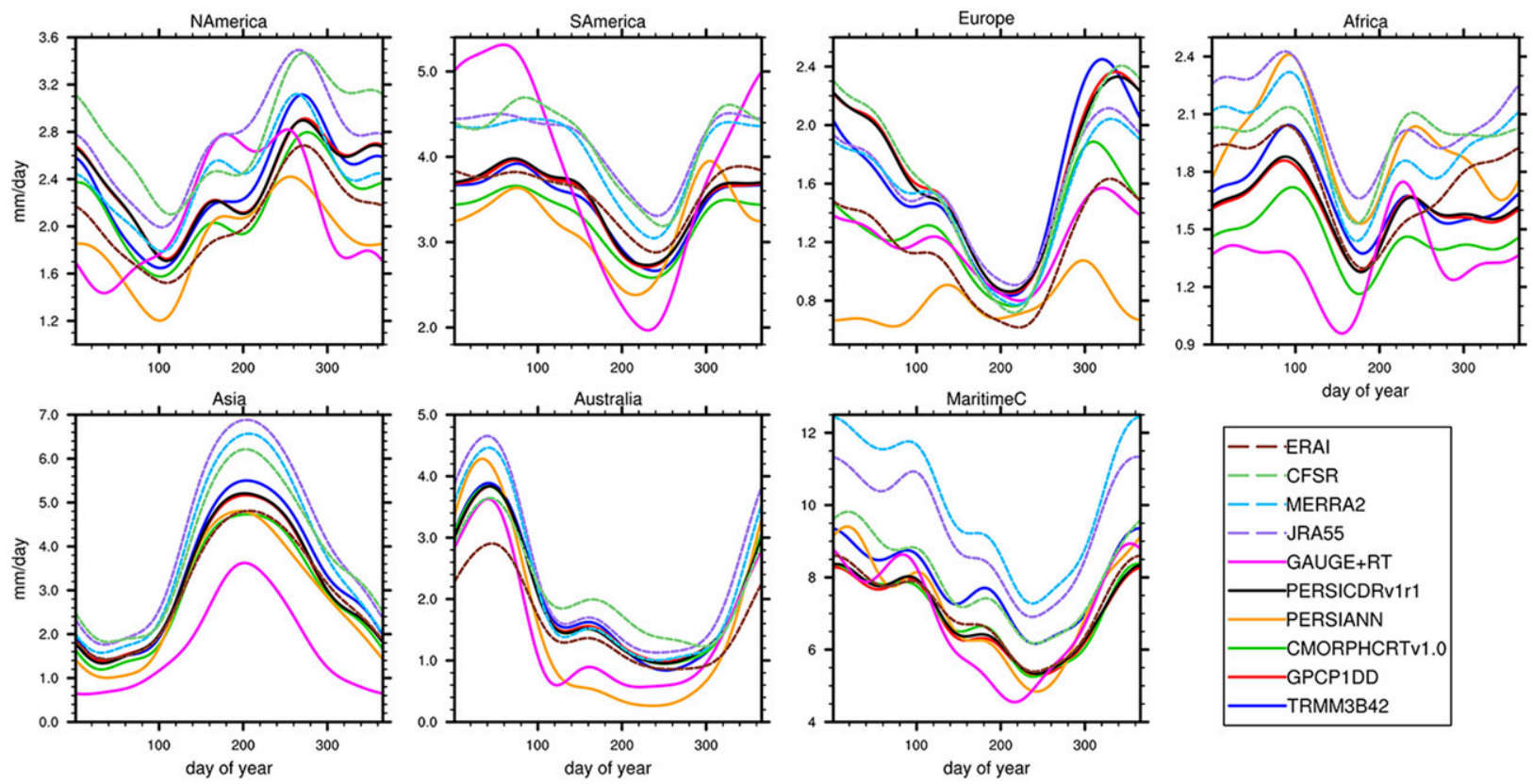

FIG. 8. Mean annual cycle for the 10 datasets at $1^{\circ}$ daily resolution for $2001-12$ averaged over the continental regions. The annual cycle is computed as the first four harmonics of the mean daily seasonal cycle at each grid point and then averaged over the continental regions. Reanalyses are shown as dashed curves and observations with solid lines. Note that the $y$-axis limits are different for all regions and that the lower limit is not always zero.

shown in Fig. 9. The interannual variability that can be seen in the annual means is somewhat consistent among most datasets, although there appears to be an offset of $0.5-1 \mathrm{~mm} \mathrm{day}^{-1}$ between the estimates (Fig. 9a), and this decreases to $0.3 \mathrm{~mm}$ day $^{-1}$ when anomalies from the seasonal cycle are considered (not shown). The outliers for annual averages are PERSIANN and to a lesser degree MERRA-2 and CFSR. CFSR appears to have a positive trend from 2001 to 2010 not seen in the other estimates; this is mostly due to trends over South America and Africa (not shown) and can be related to the changing observing system (Trenberth et al. 2011). Previous studies have shown that precipitation from reanalyses that assimilate moisture from satellite observations are strongly affected by changes in the observing system and result in spurious trends in the precipitation estimates (Trenberth et al. 2011). PERSIANN has anomalously high rain rates from late 2006 to early 2007 and anomalously low rates in late 2005 and early 2008 (Fig. 9b). Over the global ocean the differences among annual averages are larger, up to $2 \mathrm{~mm} \mathrm{day}^{-1}$, and the reanalyses have a small but significant upward trend not seen in the GPCP1DD, PERSICDRv1r1, and TRMM3B42 estimates (not shown). PERSIANN in contrast has a negative trend over the ocean.

Figure 10a shows that GAUGE+RT estimates lower precipitation rates over North America than
GPCP1DD, which matches what was observed in the monthly mean maps (Figs. 3 and 4). The only observational estimate with lower estimates over North America is CMORPHCRTv1.0. The timing of the seasonal cycle over North America is captured more or less consistently by all estimates (Fig. 10b), but the amplitude is not. CMORPHCRTv1.0 and PERSIANN underestimate winter precipitation rates relative to other analyses by up to $1 \mathrm{~mm}^{-1 a y}{ }^{-1}$ on monthly time scales, while ERAI underestimates summer precipitation rates. On weekly time scales the differences can be as large as $3 \mathrm{~mm} \mathrm{day}^{-1}$ in the winter, with PERSIANN estimating $<0.5 \mathrm{~mm} \mathrm{day}^{-1}$ and all other estimates averaging between 2.5 and $3 \mathrm{~mm} \mathrm{day}^{-1}$ (Fig. 10c). This large difference illustrates a known issue with PERSIANN and other satellite-only products. Several studies have shown that wintertime precipitation is severely underestimated in these products for different regions in the northern midlatitudes (Sapiano and Arkin 2009; Sohn et al. 2010; Kidd et al. 2012). Relative differences over North America in the summer are of the same order as over the Maritime Continent, even though total amounts are much larger over the Maritime Continent.

To assess the consistency of the time evolution among the datasets, we consider correlations on annual, monthly, and daily time scales with GPCP1DD 

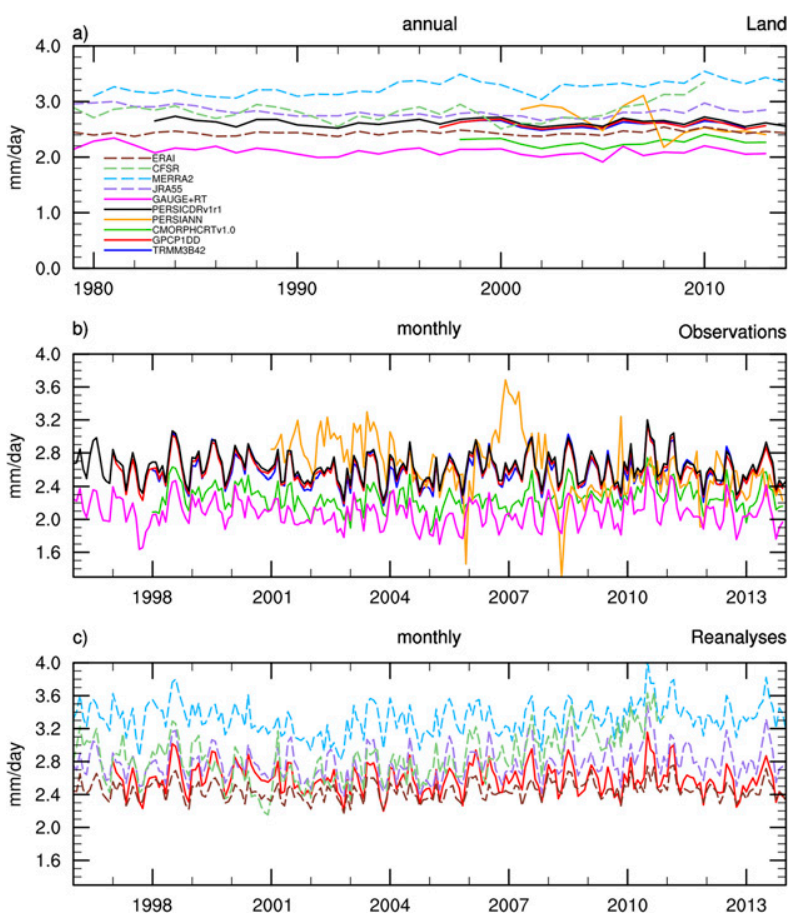

FIG. 9. Time series of rain rates averaged over global land area between $49^{\circ} \mathrm{N}$ and $49^{\circ} \mathrm{S}$ for (a) annual means, (b) monthly means of observational estimates, and (c) monthly means of reanalyses; GPCP1DD is included in (c) as a reference for comparison with (b). Reanalyses are shown as dashed curves and observations with solid lines.

and GAUGE+RT. One note of caution is necessary for interpreting the annual time scale results. The time series of annual means have only 12 data points from 2001 to 2012. This severely limits the sample size and leads to unstable estimates of the correlations on annual time scales. We show results for correlation with GPCP1DD only, but mention how these compare with correlations with GAUGE+RT. Note that, as mentioned earlier, these two datasets are both strongly dependent on rain gauge analyses and therefore make use of the same data to some degree. This also holds for several of the other precipitation estimates. Correlations of the time series of continental mean precipitation anomalies with GPCP1DD reveal large positive correlations on annual, monthly, and daily time scales for some datasets, such as TRMM3B42 and PERSICDRv1r1 in particular (Table 4). For other datasets the correlations were generally not significantly different from zero on annual and daily time scales (e.g., PERSIANN), but they were on monthly time scales.

Results for reanalyses are mixed. Correlations on annual time scales are not significant for three reanalyses over North America (JRA-55, CFSR, and
ERAI), but these exceed 0.79 for all reanalyses over Europe, the Maritime Continent (except MERRA-2), and Australia. Meanwhile, correlations remain fairly high for both monthly and daily time scales. Comparison of correlations with GAUGE+RT instead of GPCP1DD (not shown) reveal that for North America on annual time scales all datasets except PERSIANN have correlations higher than 0.8 with GAUGE+RT. Over Europe the datasets having higher correlation with GPCP1DD are TRMM3B42, PERSICDRv1r1, MERRA, and ERAI, and datasets with higher correlation with GAUGE+RT are CMORPHCRTv1.0, MERRA-2, and CFSR. On monthly time scales both CMORPHCRTv1.0 and MERRA-2 correlate better with GAUGE+RT, while all other datasets correlate better with GPCP1DD. For daily data correlations, those between GPCP1DD and all other datasets are higher than those for GAUGE+RT, with the exception of the reanalyses over Europe.

The low correlations of large-scale (from continental to global) annual averages indicate widely varying estimates of their interannual variability. Imbalances on these scales of this important component of the global water cycle affect our ability to close the water budget (Trenberth et al. 2007, 2011), because these would need to be balanced by evaporation or runoff. Global land differences on annual time scales are about $0.8 \mathrm{~mm} \mathrm{day}^{-1}$ for the observational estimates. In terms of latent heat release this translates to differences of up to $23.2 \mathrm{~W} \mathrm{~m}^{-2}$, which is comparable to the global land latent heat flux of $38.5 \mathrm{~W} \mathrm{~m}^{-2}$ estimated by Trenberth et al. (2009). Including the reanalyses increases the offset to $1 \mathrm{~mm}$ day $^{-1}$.

\section{d. Distributions}

In this section, we examine area-averaged precipitation distributions by season. The general behavior of these distributions is very similar among the continental areas. When plotted on a log-log scale (shown in the supplemental material), the distribution curves have two distinct slopes, positive for low rain rates and negative for higher rain rates. The transition between these slopes is more abrupt in the summer and more gradual in the winter months for North America (see Fig. A.47 in the supplemental material). For Africa and the Maritime Continent, the transition is abrupt for all months (see Figs. A.48 and A.52). This relationship appears to hold for all continental areas during the summer months when precipitation tends to be in a more convective regime, which leads us to speculate that the manner of transition between slopes could be related to the dominant precipitation regime (large-scale vs convective). While the location of where the slopes change in the 

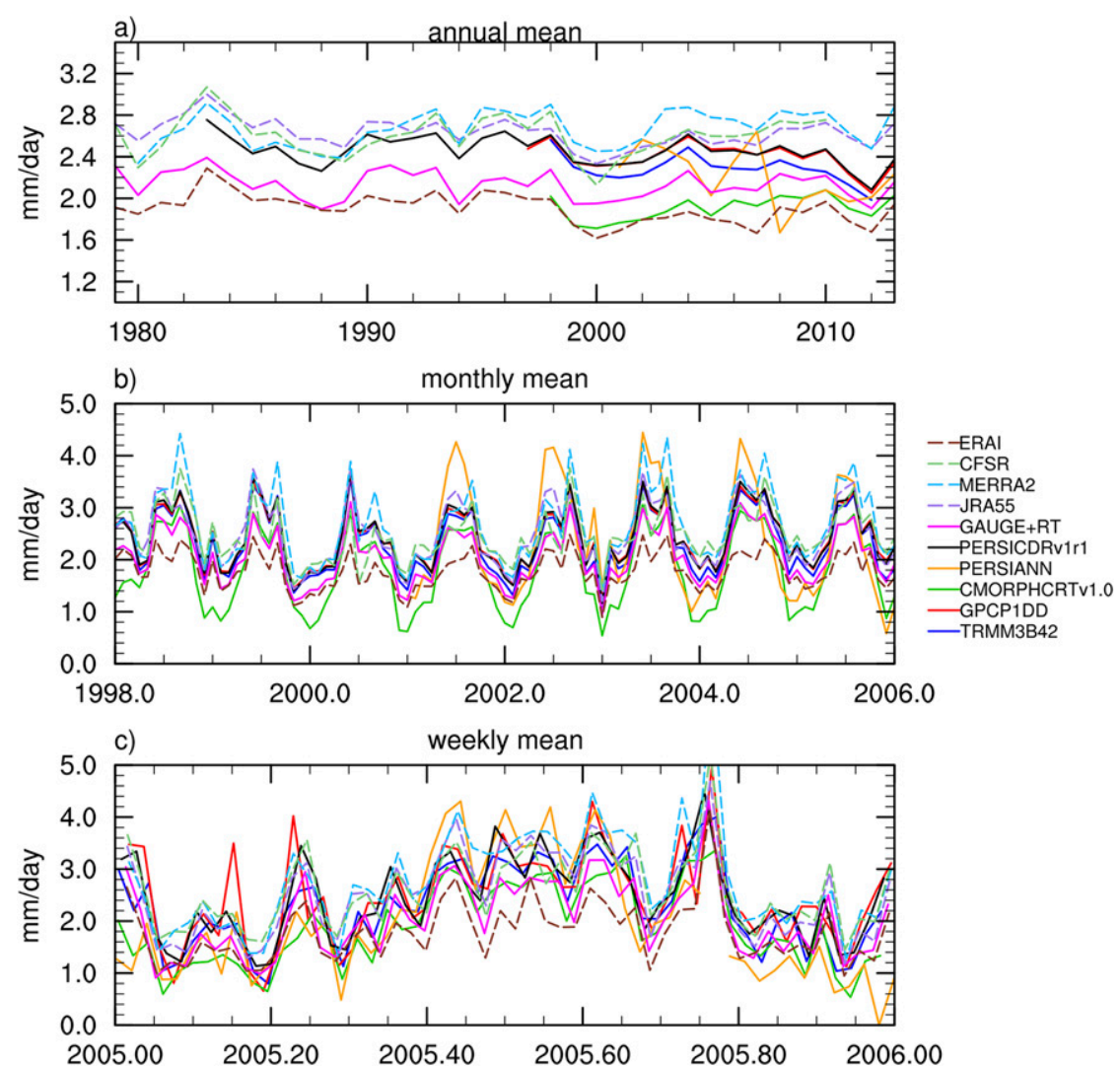

FIG. 10. Time series of rain rates averaged over North America land area between $15^{\circ}$ and $49^{\circ} \mathrm{N}$ for (a) annual means, (b) monthly means, and (c) weekly means. Reanalyses are shown as dashed curves and observations with solid lines.

$\log -\log$ plot is around $0.5 \mathrm{~mm} \mathrm{day}^{-1}$ for all seasons and regions, the slopes are quite variable among months, datasets, and regions.

Figure 11 shows the area-averaged seasonal distributions for North America. At the lowest precipitation rates, CMORPHCRTv1.0 has a positive bias, with lower rain rates being more common than in other reanalyses or observational datasets. This is consistent with all other continental areas except Africa and Australia. This low precipitation rate bias can also be seen in the older version of CMORPH that has not been bias corrected. Over Australia, ERAI has a high bias at low rain rates in austral summer and PERSIANN in austral winter. ERAI distributions over Australia, Africa, and Asia are bimodal, unlike the other precipitation estimates. The bulk of the distribution is between 0.01 and $1 \mathrm{~mm} \mathrm{~h}^{-1}$, with the peak in the distribution shifting between $0.015 \mathrm{~mm} \mathrm{~h}^{-1}$ in the winter and $0.5 \mathrm{~mm} \mathrm{~h}^{-1}$ in the summer for North America (Fig. 11c). In general, reanalyses, and ERAI in particular, dominate the distribution at these rates. For midlatitude continental regions, CMORPHCRTv1.0 (as well as PERSIANN to a lesser degree) is much less likely than other products to have precipitation occur at the intermediate rates $0.01-1 \mathrm{~mm} \mathrm{~h}^{-1}$. Figure 12 examines the differences in the tails of the precipitation distributions. Overall reanalyses tend to not produce very high rain rates, with the exception of MERRA-2. This could be because of the grid area versus point estimate, the convective parameterizations used, or the relatively large grid size. For North America in the winter TRMM3B42 has the highest rain rates and highest probability of high rates occurring (Fig. 12a). In the summer (Fig. 12c) the satellite-only estimates dominate at the highest rain rates. For other regions MERRA-2 dominates the tails in South America, Africa, and the Maritime Continent (not shown). The satellite-only product, PERSIANN, tends to accentuate the tail of the distribution during summertime convective precipitation regimes. During months when precipitation is dominated by synoptic systems or when the ground is covered in snow (e.g., Europe in the winter months) the tails of the distributions of PERSIANN are even lower than the reanalyses. 
TABLE 4. Correlations between GPCP1DD and all other datasets for annual, monthly, and daily mean time series. Correlations are computed for common time period 2001-12 (2001-10 for CFSR) with the annual cycle removed. The annual cycle is defined as the first four harmonics of the mean daily seasonal cycle. Correlations significant at the $90 \%$ level are in boldface.

\begin{tabular}{|c|c|c|c|c|c|c|c|c|c|c|}
\hline & GAUGE+RT & TRMM3B42 & CMORPHCRTv1.0 & PERSIANN & PERSICDRv1r1 & JRA-55 & MERRA-2 & MERRA & CFSR & ERAI \\
\hline \multicolumn{11}{|c|}{ Annual } \\
\hline North America & 0.82 & 0.97 & 0.49 & 0.17 & 0.99 & 0.46 & 0.81 & 0.83 & 0.56 & 0.56 \\
\hline South America & 0.25 & 0.99 & 0.31 & -0.19 & 1.00 & 0.66 & 0.49 & 0.57 & 0.44 & 0.71 \\
\hline Europe & 0.81 & 0.97 & 0.34 & -0.01 & 0.99 & 0.92 & 0.85 & 0.95 & 0.79 & 0.88 \\
\hline Africa & 0.56 & 0.98 & 0.26 & 0.69 & 1.00 & 0.60 & 0.22 & 0.74 & 0.29 & 0.55 \\
\hline Asia & 0.77 & 0.95 & 0.76 & 0.06 & 0.99 & 0.75 & 0.75 & 0.46 & 0.48 & 0.61 \\
\hline Maritime Continent & 0.94 & 0.99 & 0.98 & 0.14 & 1.00 & 0.94 & 0.14 & 0.80 & 0.97 & 0.91 \\
\hline Australia & 0.98 & 1.00 & 0.98 & 0.85 & 1.00 & 0.95 & 0.97 & 0.95 & 0.95 & 0.98 \\
\hline \multicolumn{11}{|c|}{ Monthly } \\
\hline North America & 0.55 & 0.92 & 0.36 & 0.38 & 0.98 & 0.84 & 0.52 & 0.87 & 0.84 & 0.83 \\
\hline South America & 0.25 & 0.96 & 0.26 & 0.20 & 0.98 & 0.75 & 0.29 & 0.66 & 0.50 & 0.70 \\
\hline Europe & 0.71 & 0.95 & 0.47 & 0.27 & 0.99 & 0.95 & 0.60 & 0.95 & 0.95 & 0.94 \\
\hline Africa & 0.73 & 0.98 & 0.39 & 0.44 & 1.00 & 0.67 & 0.58 & 0.67 & 0.67 & 0.67 \\
\hline Asia & 0.88 & 0.98 & 0.83 & 0.29 & 1.00 & 0.90 & 0.86 & 0.82 & 0.82 & 0.89 \\
\hline Maritime Continent & 0.92 & 0.98 & 0.94 & 0.52 & 1.00 & 0.87 & 0.61 & 0.86 & 0.92 & 0.84 \\
\hline Australia & 0.99 & 1.00 & 0.97 & 0.78 & 1.00 & 0.96 & 0.97 & 0.96 & 0.96 & 0.98 \\
\hline \multicolumn{11}{|c|}{ Daily } \\
\hline North America & 0.28 & 0.75 & 0.62 & 0.03 & 0.91 & 0.71 & 0.57 & 0.60 & 0.68 & 0.65 \\
\hline South America & 0.23 & 0.83 & 0.70 & -0.01 & 0.91 & 0.71 & 0.57 & 0.65 & 0.63 & 0.64 \\
\hline Europe & 0.48 & 0.78 & 0.60 & 0.02 & 0.90 & 0.67 & 0.55 & 0.64 & 0.66 & 0.64 \\
\hline Africa & 0.31 & 0.87 & 0.71 & -0.02 & 0.96 & 0.72 & 0.63 & 0.61 & 0.52 & 0.63 \\
\hline Asia & 0.34 & 0.86 & 0.84 & -0.06 & 0.96 & 0.81 & 0.79 & 0.69 & 0.77 & 0.75 \\
\hline Maritime Continent & 0.40 & 0.92 & 0.91 & -0.03 & 0.99 & 0.81 & 0.80 & 0.76 & 0.81 & 0.76 \\
\hline Australia & 0.65 & 0.90 & 0.89 & -0.00 & 0.97 & 0.85 & 0.86 & 0.80 & 0.82 & 0.82 \\
\hline
\end{tabular}

A different way to compare the datasets is through the distribution of the rain amount by rain rate (Fig. 13). Precipitation amount distributions tend to be skewed in a logarithmic plot, with a long tail toward lower rain rates. Rain rates below $0.01 \mathrm{~mm} \mathrm{~h}^{-1}$ are very common, but the actual rain amount from precipitation at these rates does not add up to much. During the winter months (Fig. 13a), the distributions for CMORPHCRTv1.0 and PERSIANN are much flatter, and the mean total precipitation amount of CMORPHCRTv1.0 in DJF is $29 \mathrm{~mm}$, whereas it is $56 \mathrm{~mm}$ for GPCP1DD and $66 \mathrm{~mm}$ for CFSR. That is a difference of more than $200 \%$ for the mean seasonal total estimate. Excluding CFSR, which has been shown to overestimate moisture transport from ocean to land and where at least some of the precipitation over land is due to the analysis increment (Trenberth et al. 2011), there is still a factor of 2 difference. On the other hand, in summer (Fig. 13c), PERSIANN has many high rain rate events compared to the other estimates, and the seasonal mean totals are correspondingly higher than the other estimates, confirming what was already seen in the time series results. One thing to note about the reanalysis estimates is that the rain amount distributions tend to be narrower than the satellite and rain gauge estimates. This is most obvious for ERAI (Fig. 13c) and becomes more severe for reanalyses with a coarser spatial resolution (not shown), highlighting the fact that reanalyses only resolve a narrow band of rain rates. One notable exception to this is MERRA-2, which has equally high rain rates as PERSIANN. While this may lead to positive results in midlatitude regions, it leads to estimated precipitation totals that are too large (compared to the other estimates) by a factor of 2 over the Maritime Continent.

\section{Summary and discussion}

A comparison of several global precipitation estimates and reanalyses was performed on a range of temporal and spatial scales. Only datasets with daily or higher temporal resolution were considered. To minimize differences in the datasets due to resolution, all datasets were interpolated to match that with the coarsest resolution (GPCP1DD). We found that while patterns of means and variance were largely consistent among datasets, the differences in means and variances between the datasets were often as large as the analyzed means and variances themselves.

Correlations among the precipitation estimates averaged over continental areas varied significantly. GPCP1DD, TRMM3B42, and PERSICDRv1r1 were very highly correlated. This was by construction on monthly and annual time scales, since all three datasets are bias corrected to monthly satellite-rain gauge 

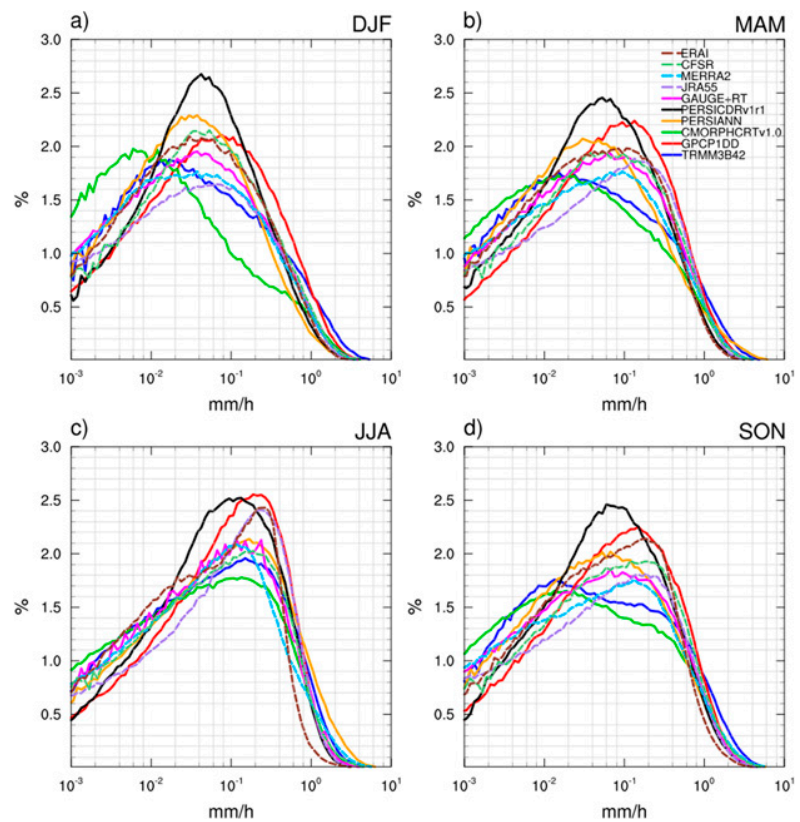

FIG. 11. Percentage distribution of precipitation rate over land area for North America $\left(15^{\circ}-49^{\circ} \mathrm{N}, 195^{\circ}-310^{\circ} \mathrm{E}\right)$, showing the climatological distribution for (a)-(d) all seasons for 2001-12. Precipitation rates are binned with logarithmic bin sizes to account for more frequent rain events at low rain rates. The $x$ axis is plotted on a log scale and the $y$ axis on a linear scale to compare the bulk of the distribution, not the tails. The black line shows the size of the bin at each precipitation rate. Distributions are computed for each month and grid point separately and then averaged over area and season. Reanalyses are shown as dashed curves and observations with solid lines. All datasets are at $1^{\circ}$ daily resolution.

analyses. These use, and tend to be dominated by, the same GPCC analysis, with the same undercatch correction applied in all cases. This conclusion also carried over to daily averages. Correlations of the satelliteonly product, PERSIANN, with GPCP1DD were generally not significantly different from zero on annual and daily time scales, but they were on monthly time scales. Reanalyses had high correlations with GPCP1DD on monthly time scales, but the results were mixed for annual averages. Correlations between reanalyses and GPCP1DD were found to be larger than 0.8 over Europe and Australia, but results were mixed over North America. This is noteworthy, because North America is one of the best observed regions in the world, and thus the potential for constraining reanalyses with observations is high. It is also interesting to note that annual correlations with GAUGE+RT were comparable and larger than 0.79 for Europe, Australia, and North America. This difference in the correlations with GPCP1DD versus GAUGERT in data dense regions could reflect a difference in the data sources the different products assimilate.
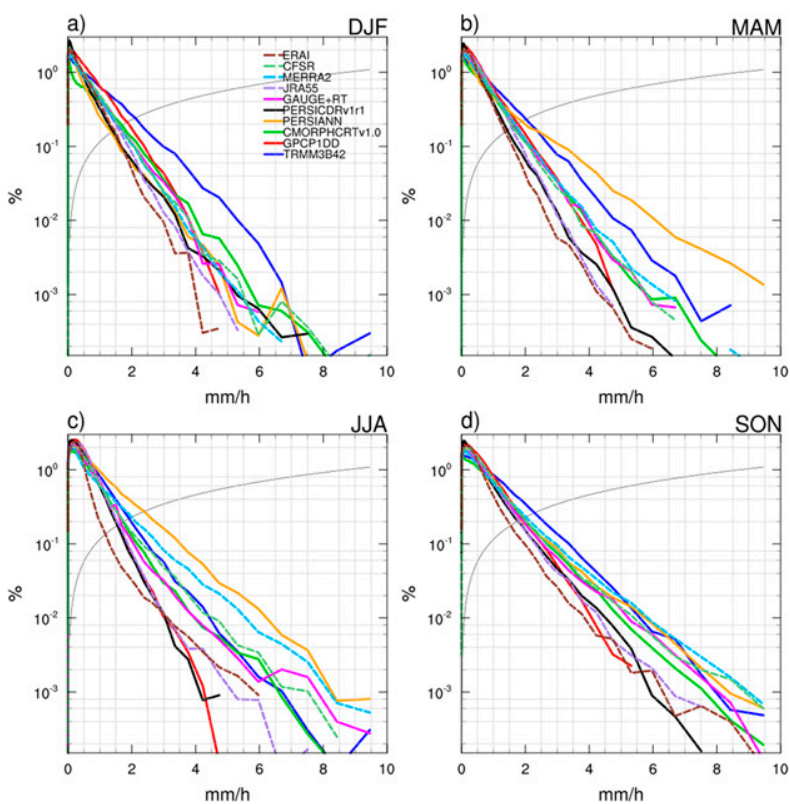

FIG. 12. Percentage distribution of precipitation rate over land area for North America $\left(15^{\circ}-49^{\circ} \mathrm{N}, 195^{\circ}-310^{\circ} \mathrm{E}\right)$. As in Fig. 11, except that the $x$ axis is plotted on a linear scale and the $y$ axis on a log scale to facilitate comparison of the tails of the distributions. Reanalyses are shown as dashed curves and observations with solid lines. All datasets are at $1^{\circ}$ daily resolution.

The time scale dependence of the correlations permits speculation on some aspects of these precipitation estimates at different scales. The nature of the correlations, which are low at annual and daily and higher at monthly time scales for time series averaged over large regions, could be interpreted to suggest that bias differences are large compared to interannual variability and random errors are large at daily time scales, but that at intermediate time scales (monthly in this case) the signal-to-noise ratio can be large enough to result in high correlations. It would also appear that monthly bias corrections increase daily correlations (e.g., PERSICDRv1r1 and TRMM3B42 correlations with GPCP1DD), possibly suggesting that the low correlations on daily time scales in satellite-only products are a result of random errors and monthly bias.

Distributions of precipitation rates and amounts confirmed a known bias in satellite-only estimates and showed that PERSIANN underestimated wintertime precipitation in midlatitudes, while overestimating midlatitude summertime precipitation. Reanalyses tended to precipitate over too narrow of a range of rain rates when compared to observational estimates, although some of the reanalyses (JRA-55 and MERRA-2) estimate mean monthly totals in the same range as or even above PERSIANN in the summer. The difference 

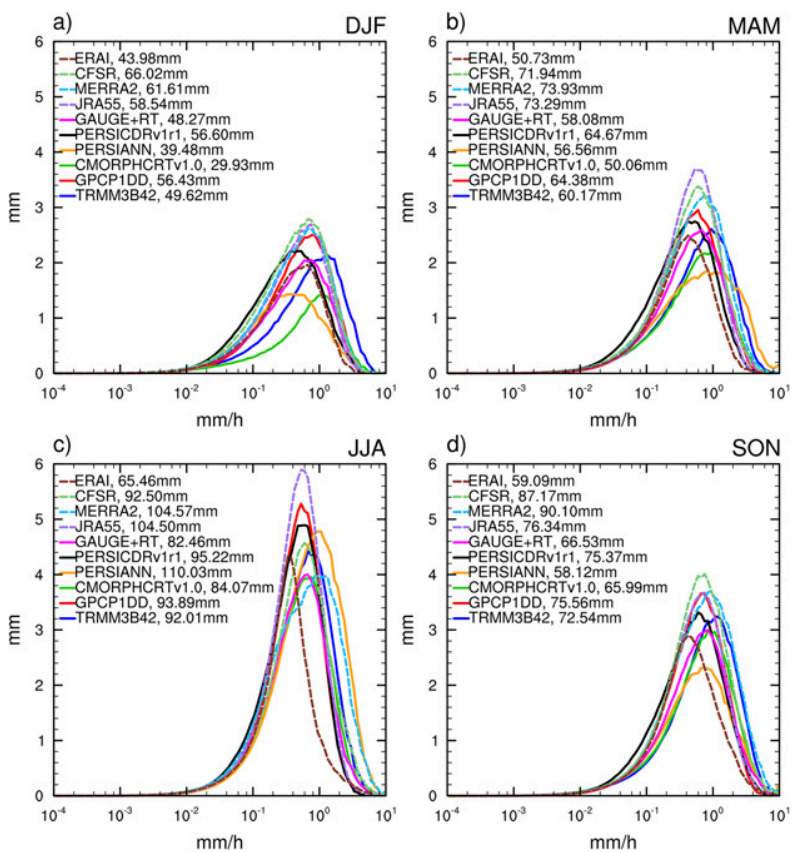

FIG. 13. Distribution of precipitation amount by precipitation rate over land area for North America $\left(15^{\circ}-49^{\circ} \mathrm{N}, 195^{\circ}-310^{\circ} \mathrm{E}\right.$; the same area as is used in Fig. 10), showing the precipitation amount distribution for (a)-(d) all seasons for 2001-12. The average is computed over the years 2001-12. Insets show average monthly totals during each season for the different estimates. Reanalyses are shown as dashed curves and observations with solid lines. All datasets are at $1^{\circ}$ daily resolution.

(at least for North America) is that the bulk of the rain in the satellite-only estimate PERSIANN comes from high rain rates $>2 \mathrm{~mm} \mathrm{~h}^{-1}$, while JRA-55 overestimation occurred at rain rates centered around $0.8 \mathrm{~mm} \mathrm{~h}^{-1}$.

Average spread among datasets was computed for each grid point, and is defined as the average of the standard deviation of anomalies from the seasonal cycle. Spread among datasets differed between reanalyses and satellite estimates (Fig. 14). Spread among reanalyses was found to be larger in the tropics and smaller in midlatitudes when compared to the spread among satellite estimates. This is likely related to midlatitude precipitation being driven mainly by the large-scale flow, with convective precipitation dominating the tropics. Reanalyses do well in representing midlatitude large-scale circulation patterns and this results in higher consistency across reanalyses in the midlatitudes. In the tropics convective parameterization was likely responsible for the bulk of the precipitation in reanalyses; these parameterizations differed widely among reanalyses and so did their precipitation estimates.

Systematic differences were found in the global precipitation estimates considered in this study. Users of these estimates need to be aware of these biases and their use as a ground truth should be limited to regimes, seasons, or regions in which the products have been shown to perform well for. For example, PERSIANN and CMORPH, designed to represent the instantaneous variability in precipitation, performed well in the tropics, but overestimated summertime convective precipitation and underestimated wintertime precipitation in midlatitudes. This suggests that the performance of CMORPH and PERSIANN in midlatitude regions always needs to be assessed for the region and season of interest prior to using these estimates.

Precipitation from reanalyses is still first and foremost a model product, influenced by observations through data assimilation, and reflects the systematic errors of the global circulation models used to provide the forecast background. There is a clear bias of the reanalyses' annual and monthly means compared to the observational estimates. However, while we showed here that large-scale (continental to global) annual averages of precipitation estimates differ in their interannual variability, variability estimated by reanalyses on monthly time scales tends to be consistent with the observational estimates (as seen from the high correlations). This suggests that studies focused mainly on the variability of precipitation may have a more reliable foundation in using reanalyses than studies investigating the energy and water budgets.

In summary, any study using precipitation estimates based on observations or reanalyses should take into account the uncertainty associated with the precipitation estimate. There is no one global precipitation product that is better than all the others for all applications. The most suitable product changes with intended application, location, and season. Therefore, care needs to be taken when choosing a product for a specific application, to ensure that the product has the capability to yield useful results. Given the uncertainty inherent in any precipitation estimate it is an asset to have several products based on different approaches available to compare and estimate that uncertainty.

In some ways precipitation estimates from satellite and reanalyses have the opposite problem. Satellite estimates perform well in regions and seasons with convective precipitation, while reanalyses are better at large scale precipitation in the midlatitudes. Precipitation estimates that incorporate both satellite- and ground-based measurements such as GPCP1DD and CMORPHCRTv1.0, and indirectly TRMM3B42 and PERSICDRv1r1, tend to lie in between the other estimates both in terms of the distributions and the average rain rates. Incorporating quality-controlled ground radar in precipitation estimates where available can be expected to have a positive impact 

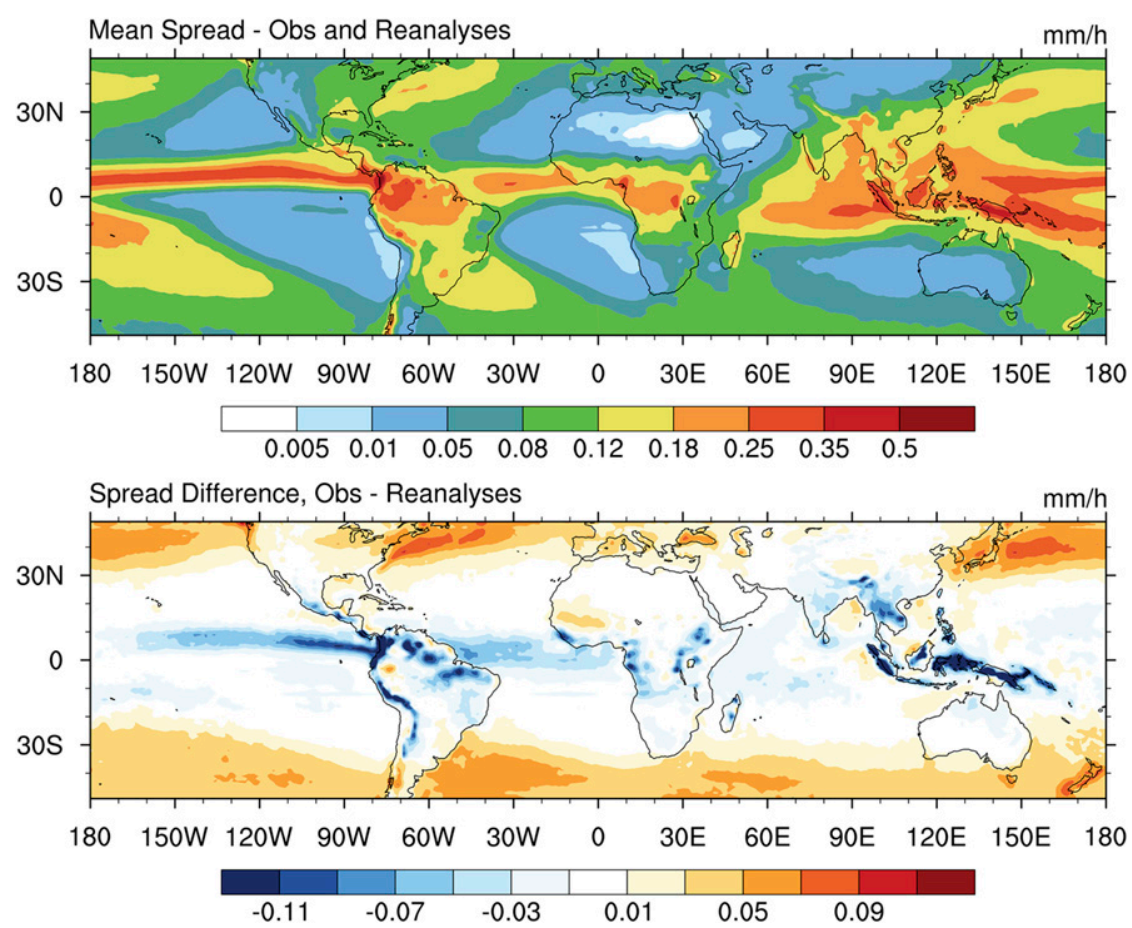

FIG. 14. Spread among precipitation estimates at $1^{\circ}$ daily resolution (computed as the mean standard deviation among datasets) for 2001-10. (top) Spread among precipitation datasets (including reanalyses). (bottom) Difference in spread among observational precipitation datasets and spread among reanalyses. The mean seasonal cycle is removed from daily data prior to computing the spread.

on the accuracy of the estimates. Including data from diverse sources (multiple satellites and retrieval channels, rain gauge, radar) appears to help with reducing errors and enhances reliability. Extending the rain gauge network to data-sparse regions, in particular over oceans, will likely have a large impact on constraining at least global mean precipitation estimates. Unfortunately, this is impractical and costly. A more practical approach may be to combine precipitation estimates from several different data sources based on their respective strengths.

Acknowledgments. Gehne's research is sponsored by the NOAA Sandy Supplemental Grant NA14NWS4830003. Hamill's research was funded by the Disaster Relief Appropriations Act of 2013. Trenberth's research is partially sponsored by DOE Office of Science Grant DE-SC0012711. We thank two anonymous reviewers for their comments and insight. We thank reviewer 1 for suggesting the particular interpretation of the correlation results. ERA-Interim data are provided courtesy of ECMWF and the Research Data Archive at the National Center for Atmospheric Research. The CFSR dataset is provided from the Climate Forecast System Reanalysis (CFSR) project carried out by the Environmental Modeling Center (EMC), National Centers for
Environmental Prediction (NCEP). The JRA-55 dataset is provided by the Japanese 55-year Reanalysis project carried out by the Japan Meteorological Agency (JMA). MERRA was developed by the Global Modeling and Assimilation Office and supported by the NASA Modeling, Analysis and Prediction Program. Source data files can be acquired from the Goddard Earth Science Data Information Services Center (GES DISC).

\section{REFERENCES}

Adam, J. C., and D. P. Lettenmaier, 2003: Adjustment of global gridded precipitation for systematic bias. J. Geophys. Res., 108, 4257, doi:10.1029/2002JD002499.

Adler, R. F., C. Kidd, G. Petty, M. Morrissey, and H. M. Goodman, 2001: Intercomparison of global precipitation products: The Third Precipitation Intercomparison Project (PIP-3). Bull. Amer. Meteor. Soc., 82, 1377-1396, doi:10.1175/ 1520-0477(2001)082<1377:IOGPPT>2.3.CO;2.

— , and Coauthors, 2003: The Version-2 Global Precipitation Climatology Project (GPCP) monthly precipitation analysis (1979-present). J. Hydrometeor., 4, 1147-1167, doi:10.1175/ 1525-7541(2003)004<1147:TVGPCP $>2.0 . C O ; 2$.

Ashouri, H., K.-L. Hsu, S. Sorooshian, D. K. Braithwaite, K. R. Knapp, L. D. Cecil, B. R. Nelson, and O. P. Prat, 2015: PERSIANN-CDR: Daily precipitation climate data record 
from multisatellite observations for hydrological and climate studies. Bull. Amer. Meteor. Soc., 96, 69-83, doi:10.1175/ BAMS-D-13-00068.1.

Becker, A., P. Finger, A. Meyer-Christoffer, B. Rudolf, K. Schamm, U. Schneider, and M. Ziese, 2013: A description of the global land-surface precipitation data products of the Global Precipitation Climatology Centre with sample applications including centennial (trend) analysis from 1901-present. Earth Syst. Sci. Data, 5, 71-99, doi:10.5194/essd-5-71-2013.

Bell, T. L., A. Abdullah, R. L. Martin, and G. R. North, 1990: Sampling errors for satellite-derived tropical rainfall: Monte Carlo study using a space-time stochastic model. J. Geophys. Res., 95, 2195-2205, doi:10.1029/JD095iD03p02195.

Bolvin, D., 2001: Global precipitation at one-degree daily resolution from multisatellite observations, version 1.2. NASA GSFC, accessed 7 August 2014. [Available online at ftp:// meso.gsfc.nasa.gov/pub/1dd-v1.2.]

Bosilovich, M. G., and Coauthors, 2015a: MERRA-2: Initial evaluation of the climate. NASA Tech. Rep. Series on Global Modeling and Data Assimilation NASA/TM-2015-104606, Vol. 43, 139 pp.

— , and Coauthors, 2015b: Modern-Era Retrospective Analysis for Research and Applications, version 2. NASA, accessed 9 February 2016. [Available online at http://disc.sci.gsfc.nasa. gov/uui/search/ (use search term MERRA-2).]

Braithwaite, D., 2000: PERSIANN 0.25 Product Access Tools. Center for Hydrometeorology and Remote Sensing, University of California, Irvine, accessed 4 August 2014. [Available online at http://chrs.web.uci.edu/persiann/data.html.]

Brown, J. D., D.-J. Seo, and J. Du, 2012: Verification of precipitation forecasts from NCEP's short-range ensemble forecast (SREF) system with reference to ensemble streamflow prediction using lumped hydrologic models. J. Hydrometeor., 13, 808-836, doi:10.1175/JHM-D-11-036.1.

Chen, M., W. Shi, P. Xie, V. B. S. Silva, V. E. Kousky, R. W. Higgins, and J. E. Janowiak, 2008: Assessing objective techniques for gauge-based analyses of global daily precipitation. J. Geophys. Res., 113, D04110, doi:10.1029/2007JD009132.

CMORPHv1.0, 2015: NOAA CPC Morphing Technique ("CMORPH"), version 1.0, CRT. NOAA Center for Weather and Climate Prediction, Climate Prediction Center, accessed 9 February 2016. [Available online at http://ftp.cpc.ncep.noaa. gov/precip/CMORPH_V1.0/CRT/.]

Daly, C., R. P. Neilson, and D. L. Phillips, 1994: A statisticaltopographic model for mapping climatological precipitation over mountainous terrain. J. Appl. Meteor., 33, 140-158, doi:10.1175/ 1520-0450(1994)033<0140:ASTMFM>2.0.CO;2.

Dee, D. P., and Coauthors, 2011a: The ERA-Interim reanalysis: Configuration and performance of the data assimilation system. Quart. J. Roy. Meteor. Soc., 137, 553-597, doi:10.1002/qj.828.

— , and Coauthors, 2011b: ERA-Interim. ECMWF, accessed 5 August 2014. [Available online at http://www.ecmwf.int/en/ research/climate-reanalysis/era-interim.]

Gu, G., and R. F. Adler, 2011: Precipitation and temperature variations on the interannual time scale: Assessing the impact of ENSO and volcanic eruptions. J. Climate, 24, 2258-2270, doi:10.1175/2010JCLI3727.1.

Gutowski, W. J., S. G. Decker, R. A. Donavon, Z. Pan, R. W. Arritt, and E. S. Takle, 2003: Temporal-spatial scales of observed and simulated precipitation in central U.S. climate. J. Climate, 16, 3841-3847, doi:10.1175/1520-0442(2003)016<3841: TSOOAS $>2.0 . \mathrm{CO} ; 2$.

Haerter, J. O., P. Berg, and S. Hagemann, 2010: Heavy rain intensity distributions on varying time scales and at different temperatures. J. Geophys. Res., 115, D17102, doi:10.1029/ 2009JD013384.

Hamill, T. M., 2012: Verification of TIGGE multimodel and ECMWF reforecast-calibrated probabilistic precipitation forecasts over the contiguous United States. Mon. Wea. Rev., 140, 2232-2252, doi:10.1175/MWR-D-11-00220.1.

Harris, I., P. Jones, T. Osborn, and D. Lister, 2014: Updated highresolution grids of monthly climatic observations-The CRU TS3.10 dataset. Int. J. Climatol., 34, 623-642, doi:10.1002/joc.3711.

Hsu, K.-L., X. Gao, S. Sorooshian, and H. V. Gupta, 1997: Precipitation estimation from remotely sensed information using artificial neural networks. J. Appl. Meteor., 36, 1176-1190, doi:10.1175/1520-0450(1997)036<1176:PEFRSI > 2.0.CO;2.

Huffman, G. J., and Coauthors, 1997: The Global Precipitation Climatology Project (GPCP) combined precipitation dataset. Bull. Amer. Meteor. Soc., 78, 5-20, doi:10.1175/ 1520-0477(1997)078<0005:TGPCPG >2.0.CO;2.

, R. F. Adler, M. M. Morrissey, D. T. Bolvin, S. Curtis, R. Joyce, B. McGavock, and J. Susskind, 2001: Global precipitation at one-degree daily resolution from multisatellite observations. J. Hydrometeor., 2, 36-50, doi:10.1175/ 1525-7541(2001)002<0036:GPAODD > 2.0.CO;2.

— , and Coauthors, 2007: The TRMM Multisatellite Precipitation Analysis (TMPA): Quasi-global, multiyear, combined-sensor precipitation estimates at fine scales. J. Hydrometeor., 8, 38-55, doi:10.1175/JHM560.1.

—, E. Stocker, D. Bolvin, E. Nelkin, and R. Adler, 2012: TRMM version $73 \mathrm{~B} 42$ and 3B43 data sets. NASA/GSFC, accessed 5 January 2014. [Available online at http://disc.sci.gsfc.nasa. gov/gesNews/trmm_v7_multisat_precip.]

Janowiak, J. E., P. Bauer, W. Wang, P. A. Arkin, and J. Gottschalck, 2010: An evaluation of precipitation forecasts from operational models and reanalyses including precipitation variations associated with MJO activity. Mon. Wea. Rev., 138, 4542-4560, doi:10.1175/2010MWR3436.1.

Joyce, B., and J. Janowiak, 2005: NOAA CPC Morphing Technique ("CMORPH"). NOAA Climate Prediction Center, accessed 7 January 2014. [Available online at http://www.cpc. ncep.noaa.gov/products/janowiak/cmorph_description.html.]

Joyce, R. J., J. E. Janowiak, P. A. Arkin, and P. Xie, 2004: CMORPH: A method that produces global precipitation estimates from passive microwave and infrared data at high spatial and temporal resolution. J. Hydrometeor., 5, 487-503, doi:10.1175/1525-7541(2004)005<0487:CAMTPG>2.0.CO;2.

Kennedy, A. D., X. Dong, B. Xi, S. Xie, Y. Zhang, and J. Chen, 2011: A comparison of MERRA and NARR reanalyses with the DOE ARM SGP data. J. Climate, 24, 4541-4557, doi:10.1175/ 2011JCLI3978.1.

Kidd, C., and G. Huffman, 2011: Global precipitation measurement. Meteor. Appl., 18, 334-353, doi:10.1002/met.284.

, P. Bauer, J. Turk, G. J. Huffman, R. Joyce, K. L. Hsu, and D. Braithwaite, 2012: Intercomparison of high-resolution precipitation products over northwest Europe. J. Hydrometeor., 13, 67-83, doi:10.1175/JHM-D-11-042.1.

Kobayashi, S., and Coauthors, 2015a: JRA-55: Japanese 55-year reanalysis, daily 3-hourly and 6-hourly data. Research Data Archive at NCAR, accessed June 2015. [Available online at http://rda.ucar.edu/datasets/ds628.0/.]

— specifications and basic characteristics. J. Meteor. Soc. Japan, 93, 5-48, doi:10.2151/jmsj.2015-001.

Lien, G.-Y., T. Miyoshi, and E. Kalnay, 2016: Assimilation of TRMM multisatellite precipitation analysis with a low-resolution 
NCEP global forecasting system. Mon. Wea. Rev., 144, 643-661, doi:10.1175/MWR-D-15-0149.1.

Lin, Y., and K. E. Mitchell, 2005: The NCEP stage II/IV hourly precipitation analyses: Development and applications. 19th Conf. on Hydrology, San Diego, CA, Amer. Meteor. Soc., 1.2. [Available online at https://ams.confex.com/ams/pdfpapers/ 83847.pdf.]

Lindvall, J., G. Svensson, and C. Hannay, 2013: Evaluation of nearsurface parameters in the two versions of the atmospheric model in CESM1 using flux station observations. J. Climate, 26, 26-44, doi:10.1175/JCLI-D-12-00020.1.

Liu, Q., and Coauthors, 2011: The contributions of precipitation and soil moisture observations to the skill of soil moisture estimates in a land data assimilation system. J. Hydrometeor., 12, 750-765, doi:10.1175/JHM-D-10-05000.1.

McLaughlin, D., Y. Zhou, D. Entekhabi, and V. Chatdarong, 2006: Computational issues for large-scale land surface data assimilation problems. J. Hydrometeor., 7, 494-510, doi:10.1175/ JHM493.1.

Meng, J., R. Yang, H. Wei, M. Ek, G. Gayno, P. Xie, and K. Mitchell, 2012: The land surface analysis in the NCEP Climate Forecast System Reanalysis. J. Hydrometeor., 13, 1621-1630, doi:10.1175/JHM-D-11-090.1.

Mesinger, F., and Coauthors, 2006: North American Regional Reanalysis. Bull. Amer. Meteor. Soc., 87, 343-360, doi:10.1175/ BAMS-87-3-343.

Peterson, T. C., and Coauthors, 1998: Homogeneity adjustments of in situ atmospheric climate data: A review. Int. J. Climatol., 18, 1493-1517, doi:10.1002/(SICI)1097-0088(19981115)18:13<1493:: AID-JOC329>3.0.CO;2-T.

Prat, O. P., and B. R. Nelson, 2015: Evaluation of precipitation estimates over CONUS derived from satellite, radar, and rain gauge data sets at daily to annual scales (20022012). Hydrol. Earth Syst. Sci., 19, 2037-2056, doi:10.5194/ hess-19-2037-2015.

Rasmussen, R., and Coauthors, 2012: How well are we measuring snow? The NOAA/FAA/NCAR winter precipitation test bed. Bull. Amer. Meteor. Soc., 93, 811-829, doi:10.1175/ BAMS-D-11-00052.1.

Rienecker, M., and Coauthors, 2011a: MERRA: NASA's Modern-Era Retrospective Analysis for Research and Applications. J. Climate, 24, 3624-3648, doi:10.1175/ JCLI-D-11-00015.1.

_ , and Coauthors, 2011b: MERRA: NASA's Modern-Era Retrospective Analysis for Research and Applications. NASA, accessed August 2014. [Available online at http://disc. sci.gsfc.nasa.gov/uui/search/\%22MERRA \%22.]

Rodell, M., and Coauthors, 2015: The observed state of the water cycle in the early twenty-first century. J. Climate, 28, 82898318, doi:10.1175/JCLI-D-14-00555.1.

Ruane, A. C., 2010a: NARR's atmospheric water cycle components. Part I: 20-year mean and annual interactions. J. Hydrometeor., 11, 1205-1219, doi:10.1175/2010JHM1193.1.

- 2010b: NARR's atmospheric water cycle components. Part II: Summertime mean and diurnal interactions. J. Hydrometeor., 11, 1220-1233, doi:10.1175/2010JHM1279.1.

Saha, S., and Coauthors, 2010a: The NCEP Climate Forecast System Reanalysis. Bull. Amer. Meteor. Soc., 91, 1015-1057, doi:10.1175/ 2010BAMS3001.1.

, and Coauthors, 2010b: The NCEP Climate Forecast System Reanalysis. Research Data Archive at NCAR, accessed August 2014. [Available online at http://rda.ucar.edu/datasets/ ds093.0/.]
Sapiano, M. R. P., and P. A. Arkin, 2009: An intercomparison and validation of high-resolution satellite precipitation estimates with 3-hourly gauge data. J. Hydrometeor., 10, 149-166, doi:10.1175/2008JHM1052.1.

Sardeshmukh, P. D., G. P. Compo, and C. Penland, 2015: Need for caution in interpreting extreme weather statistics. J. Climate, 28, 9166-9187, doi:10.1175/JCLI-D-15-0020.1.

Schlosser, C. A., and P. R. Houser, 2007: Assessing a satellite-era perspective of the global water cycle. J. Climate, 20, 13161338, doi:10.1175/JCLI4057.1.

Sevruk, B., M. Ondrás, and B. Chvila, 2009: The WMO precipitation measurement intercomparisons. Atmos. Res., 92 , 376-380, doi:10.1016/j.atmosres.2009.01.016.

Smith, E. A., J. E. Lamm, and R. Adler, 1998: Results of WetNet PIP-2 project. J. Atmos. Sci., 55, 1483-1536, doi:10.1175/ 1520-0469(1998)055<1483:ROWPP $>2.0 . C O ; 2$.

Sohn, B. J., H.-J. Han, and E.-K. Seo, 2010: Validation of satellitebased high-resolution rainfall products over the Korean Peninsula using data from a dense rain gauge network. J. Appl. Meteor. Climatol., 49, 701-714, doi:10.1175/2009JAMC2266.1.

Sorooshian, S., K. Hsu, X. Gao, H. V. Gupta, B. Imam, and D. Braithwaite, 2000: Evaluation of PERSIANN system satellite-based estimates of tropical rainfall. Bull. Amer. Meteor. Soc., 81, 2035-2046, doi:10.1175/1520-0477(2000)081<2035: EOPSSE $>2.3 . \mathrm{CO} ; 2$.

,-- D. Braithwaite, H. Ashouri, and N. C. Program, 2014: NOAA Climate Data Record (CDR) of precipitation estimation from remotely sensed information using artificial neural networks (PERSIANN-CDR), version 1 revision 1. NOAA National Climatic Data Center, accessed 28 July 2015. [Available online at ftp://data.ncdc.noaa.gov/cdr/persiann/files/.]

Stephens, G. L., and Coauthors, 2010: Dreary state of precipitation in global models. J. Geophys. Res., 115, D24211, doi:10.1029/ 2010JD014532.

Susskind, J., P. Piraino, L. Rokke, L. Iredell, and A. Mehta, 1997: Characteristics of the TOVS Pathfinder Path A dataset. Bull. Amer. Meteor. Soc., 78, 1449-1472, doi:10.1175/ 1520-0477(1997)078<1449:COTTPP>2.0.CO;2.

Trenberth, K. E., and D. J. Shea, 2005: Relationships between precipitation and surface temperature. Geophys. Res. Lett., 32, L14703, doi:10.1029/2005GL022760.

— Transports from ocean to land. J. Climate, 26, 7837-7851, doi:10.1175/JCLI-D-13-00008.1.

_ A. Dai, R. M. Rasmussen, and D. B. Parsons, 2003: The changing character of precipitation. Bull. Amer. Meteor. Soc., 84, 1205-1217, doi:10.1175/BAMS-84-9-1205.

_- L. Lmith, T. Qian, A. Dai, and J. Fasullo, 2007: Estimates of the global water budget and its annual cycle using observational and model data. J. Hydrometeor., 8, 758-769, doi:10.1175/JHM600.1

_ J. T. Fasullo, and J. Kiehl, 2009: Earth's global energy budget. Bull. Amer. Meteor. Soc., 90, 311-323, doi:10.1175/2008BAMS2634.1.

,-- , and J. Mackaro, 2011: Atmospheric moisture transports from ocean to land and global energy flows in reanalyses. J. Climate, 24, 4907-4924, doi:10.1175/2011JCLI4171.1.

—_, A. Dai, G. van der Schrier, P. D. Jones, J. Barichivich, K. R. Briffa, and J. Sheffield, 2014: Global warming and changes in drought. Nat. Climate Change, 4, 17-22, doi:10.1038/ nclimate2067.

Wilcox, E. M., and L. J. Donner, 2007: The frequency of extreme rain events in satellite rain-rate estimates and an atmospheric general circulation model. J. Climate, 20, 53-69, doi:10.1175/JCLI3987.1. 
Wolff, D. B., and B. L. Fisher, 2008: Comparisons of instantaneous TRMM ground validation and satellite rain-rate estimates at different spatial scales. J. Appl. Meteor. Climatol., 47, 22152237, doi:10.1175/2008JAMC1875.1.

Xie, P., 2009: CPC unified gauge-based analysis of global daily precipitation. NOAA Climate Prediction Center, accessed 5 August 2014. [Available online at http://ftp.cpc.ncep.noaa. gov/precip/CPC_UNI_PRCP.]

_, and P. A. Arkin, 1997: Global precipitation: A 17-year monthly analysis based on gauge observations, satellite estimates, and numerical model outputs. Bull. Amer. Meteor.
Soc., 78, 2539-2558, doi:10.1175/1520-0477(1997)078<2539: GPAYMA $>2.0 . \mathrm{CO} ; 2$.

, M. Chen, S. Yang, A. Yatagai, T. Hayasaka, Y. Fukushima, and C. Liu, 2007: A gauge-based analysis of daily precipitation over East Asia. J. Hydrometeor., 8, 607-627, doi:10.1175/ JHM583.1.

Yatagai, A., K. Kamiguchi, O. Arakawa, A. Hamada, N. Yasutomi, and A. Kitoh, 2012: APHRODITE: Constructing a long-term daily gridded precipitation dataset for Asia based on a dense network of rain gauges. Bull. Amer. Meteor. Soc., 93, 14011415, doi:10.1175/BAMS-D-11-00122.1. 